Phonological Data \& Analysis Volume 2, Article 3: 1-37 (2020)

https://doi.org/10.3765/pda.v2art3.14

Received 18 October 2018; revised 26 September 2019; accepted 16 October 2019. C 2020 Adam G. McCollum \& James Essegbey. Published by the Linguistic Society of America with permission of the authors under a CC BY 3.0 license.

\title{
Initial prominence and progressive vowel harmony in Tutrugbu
}

\author{
Adam G. McCollum ${ }^{\mathrm{a}}$ \& James Essegbey ${ }^{\mathrm{b}^{*}}$ \\ aRutgers University - adam.mccollum@rutgers.edu \\ bUniversity of Florida - essegbey@ufl.edu
}

\begin{abstract}
One of the key elements of constraint-based formalisms is their ability to derive a variety of effects from the interaction of general constraints. As for vowel harmony, one persistent question within Optimality Theory is how to encode directionality - directly through directional harmony-driving constraints, or indirectly through asymmetric prominence patterns. This paper presents a typologically unusual case of progressive harmony triggered by prefixes in Tutrugbu. We compare analyzing harmony as purely progressive in a direct sense with an indirect analysis that motivates harmony from initial-syllable prominence. Based on both language-internal and typological evidence, we argue that the prominencebased analysis is superior. We generalize to suggest that progressive harmony should always be reducible to independent factors, and as a result, formalized indirectly through prominence.
\end{abstract}

Keywords: vowel harmony; directionality; prominence; typology; Kwa

\section{Introduction}

One of the key elements of constraint-based formalisms, most notably Optimality Theory (Prince \& Smolensky 2004; OT), is their ability to derive a variety of effects from the interaction of general constraints. For vowel harmony, how to derive directionality is a persistent question in OT. A significant body of work has sought to derive directionality in vowel harmony from prominence. Under this approach, all directionality is epiphenomenal (Beckman 1997; Baković 2000; Walker 2011), and need not be encoded in the formalism. However, others have treated directionality as a theoretical primitive, which is directly and necessarily encoded in the analysis (Kirchner 1993; Padgett 1995; Mahanta 2007). Hyman (2002, 2008) pursues a hybrid analysis, arguing that directionality is typically determined by morphological prominence (i.e. root control), but when harmony is not reducible to root-control, it is always regressive. In this paper, we present evidence for progressive harmony that is not root-controlled. We demonstrate that labial harmony in Tutrugbu is prefix-initiated and progressive, counter to Hyman's claim.

In Tutrugbu, initial prefixes containing round vowels trigger rounding on following prefix vowels. Observe the data below in (1). In $(1 \mathrm{a}, \mathrm{b})$ the future prefix surfaces as [ba] after unrounded initial vowels. In $(1 \mathrm{c}, \mathrm{d})$ though, FUT is rounded to [bo] after initial [o].

\footnotetext{
${ }^{*}$ We would like to thank the Tutrugbu speakers who shared their language with us, in addition to Sharon Rose, Eric Baković, and Ginger Boyd for their insightful comments on earlier drafts. We would also like to thank Rachel Walker and three reviewers at Natural Language \& Linguistic Theory, as well as Eugene Buckley and two anonymous PDA reviewers for their immensely useful feedback. Any errors are almost certainly the first author's.
} 
(1) Tutrugbu progressive labial harmony ${ }^{1}$
a. $\varepsilon^{\mathrm{H}}$-ba-bá
'1S-FUT-come'
b. a-ba-bá
'3S-FUT-come'
c. o-bo-bá *o-ba-bá
'2S-FUT-come'
d. no-bo-bá *no-ba-bá
'2S-FUT-come'

We lay out two possible analyses of the Tutrugbu data - either that progressive harmony falls out from asymmetrical prominence relations, or that labial harmony in the language is the best evidence for purely progressive harmony that operates completely independent of prominence. If harmony derives from prominence relations, then we must recast Hyman's $(2002,2008)$ definition of prominence to account for the Tutrugbu data. If, however, harmony is best analyzed as purely progressive here, this suggests that we must allow for parametric variation for directionality, similar to derivational analyses (e.g. Chomsky \& Halle 1968; Archangeli \& Pulleyblank 1994; Nevins 2010). We compare the two analyses, ultimately arguing in favor of the prominence-based analysis as a better account of language-internal facts, as well as the larger typology of prefix-initiated harmony patterns. As a result, we expand Hyman's analysis such that the directionality of harmony is either derivable from some source of prominence, including edge prominence, or it is purely regressive.

The paper is organized as follows. In $\S 2$, we describe labial harmony in Tutrugbu. In $\S 3$, we lay out the two competing analyses. We introduce three diagnostics to differentiate between the two, comparing Tutrugbu and several other prefix-initiated harmony patterns to purely regressive harmony in Karajá (Ribeiro 2002). In §4, we develop a correspondence-based analysis of harmony in the language. In $\S 5$, we address residual issues from the analysis and discuss the broader typology of directionality in harmony. Finally, in $\S 6$ we conclude the paper.

\section{Tutrugbu}

Tutrugbu is one of 15 Ghana-Togo Mountain languages of the Kwa (Benue-Congo) language family. ${ }^{2}$ The language is closely related to neighboring Tafi and Avatime. ${ }^{3}$ These languages are surrounded by Ewe, the dominant regional language. The Ewe name for Tutrugbu is Nyagbo (also spelled Nyangbo), which is also the official name of the language.

The data presented throughout the paper derive from a corpus of natural speech collected during documentary fieldwork in southeastern Ghana, as well as formal elicitation conducted both in Ghana and the United States.

\subsection{Vowel inventory}

The Tutrugbu vowel inventory consists of nine underlying and seven surface oral vowels, presented below in (2); see also Essegbey (2009, 2010, 2012); McCollum \& Essegbey (2018); and McCollum et al. (2019). The underlying vowel inventory is very similar to those in neighboring Tafi and Avatime; the only substantive difference lies in what we have transcribed as $/ \varepsilon^{\mathrm{H}} \rho^{\mathrm{H}} /$ in Tutrugbu instead of $/ \mathrm{I} \mho /$ in Tafi and Avatime (see Bobuafor 2013: 27-29 for Tafi; for the Avatime inventory, see Maddieson 1995; Schuh 1995: $38-45)$. In Tutrugbu, only two surface high vowels are present, [i] and $[\mathrm{u}]$, with underlying $/ \varepsilon^{\mathrm{H}} \rho^{\mathrm{H}} / \mathrm{being}$

\footnotetext{
${ }^{1} / \varepsilon^{\mathrm{H}} /$ represents a surface mid vowel that is phonologically [+hi]. This is further discussed in $\S \S 2-3$ and $\S 5$.

2 Throughout the paper we use the following abbreviations along with standard Leipzig glossing abbreviations: $\mathrm{CMX}=$ class marker for class $\mathrm{x}, \mathrm{CONT}=$ continuative, $\mathrm{CTFG}=$ centrifugal, $\mathrm{DEP}=$ dependent pronoun, $\mathrm{EMPH}=\mathrm{emphatic}$, $\mathrm{EXC}=$ excessive, $\mathrm{FV}=$ final vowel, $\mathrm{HAB}=$ habitual, $\mathrm{ITV}=$ itive, $\mathrm{REV}=$ reversive, $\mathrm{SMX}=$ subject marker for class $\mathrm{X}$, and VENT $=$ ventive.

${ }^{3}$ In fact, Tutrugbu and Tafi are so closely related that they are sometimes treated as dialects of the same language (Heine 1968; Dakubu \& Ford 1988), and some have treated Tutrugbu, Tafi, as well as Avatime as dialects of a single language (Dakubu 2009)
} 
neutralized with $/ \varepsilon \rho /$ to $[\varepsilon \rho]$ on the surface. The vowels $/ \varepsilon^{\mathrm{H}} \rho^{\mathrm{H}} /$ are thus marked with a superscript $H$ to indicate that they are phonologically [+high] despite their surface quality. Throughout the paper $/ \varepsilon^{\mathrm{H}} \rho^{\mathrm{H}} /$ are distinguished from $/ \varepsilon$ o/ to account for their abstract phonological behavior. As we discuss in Section 5.1, there is no discernible surface difference between $[\varepsilon]$ and $\left[\varepsilon^{\mathrm{H}}\right]$, and $[0]$ and $\left[{ }^{\mathrm{H}}\right]$. The abstract phonological difference between these two pairs will play a key role in our analysis of labial harmonic alternations discussed below.

\begin{tabular}{cccc}
\multicolumn{2}{c}{ underlying vowel inventory } & surface vowel inventory \\
$\mathrm{i}$ & $\mathrm{u}$ & $\mathrm{i}$ & $\mathrm{u}$ \\
$\varepsilon^{\mathrm{H}}$ & $\rho^{\mathrm{H}}$ & $\mathrm{e}$ & \\
$\mathrm{e}$ & $\mathrm{o}$ & $\varepsilon$ & 0 \\
$\varepsilon$ & 0 & $\mathrm{a}$ &
\end{tabular}

Although the focus of the paper is on progressive labial harmony, the language also exhibits regressive ATR harmony that is referenced at a number of points in the description and discussion. The ATR harmony sets are shown below in (3). Among these, note that /a/ pairs with /e/ for harmony. This same pairing is attested in Tafi and Avatime (Bobuafor 2013; Schuh 1995). The mid round vowels, /o o/, are paired together, and two abstract pairings are also present, $/ \mathrm{o}^{\mathrm{H}} \mathrm{u} /$ and $/ \varepsilon^{\mathrm{H}} \mathrm{i} /$. Finally, the mid vowel $/ \varepsilon /$ is unpaired for harmony. Moreover, this vowel does not occur in prefixes, so it does not factor into either labial or ATR harmony, which both operate over prefixes. We assume throughout that [-ATR] and [-round] are the unmarked feature values. When labial harmony does not apply, medial prefixes all surface as [-round]. Additionally, when ATR harmony fails, prefix vowels surface as [-ATR].

(3) ATR vowel classes and harmonic pairings

$\begin{array}{cc}{[-\mathrm{ATR}]} & {[+\mathrm{ATR}]} \\ \mathrm{a} & \mathrm{e} \\ 0 & \mathrm{o} \\ \rho^{\mathrm{H}} & \mathrm{u} \\ \varepsilon^{\mathrm{H}} & \mathrm{i} \\ \varepsilon & \end{array}$

The surface vowel inventory is plotted below in Figure 1. Eight tokens of each vowel $(n=56)$ in root-initial position were culled from an approximately 1,300-word audio dictionary produced by a single female speaker. F1-F2 measurements were made at the midpoint of each vowel. Most oral vowels in Tutrugbu also have nasal counterparts (all except /ẽ/ and /õ/), but they behave just like oral vowels with respect to harmony, and are therefore excluded from discussion. 


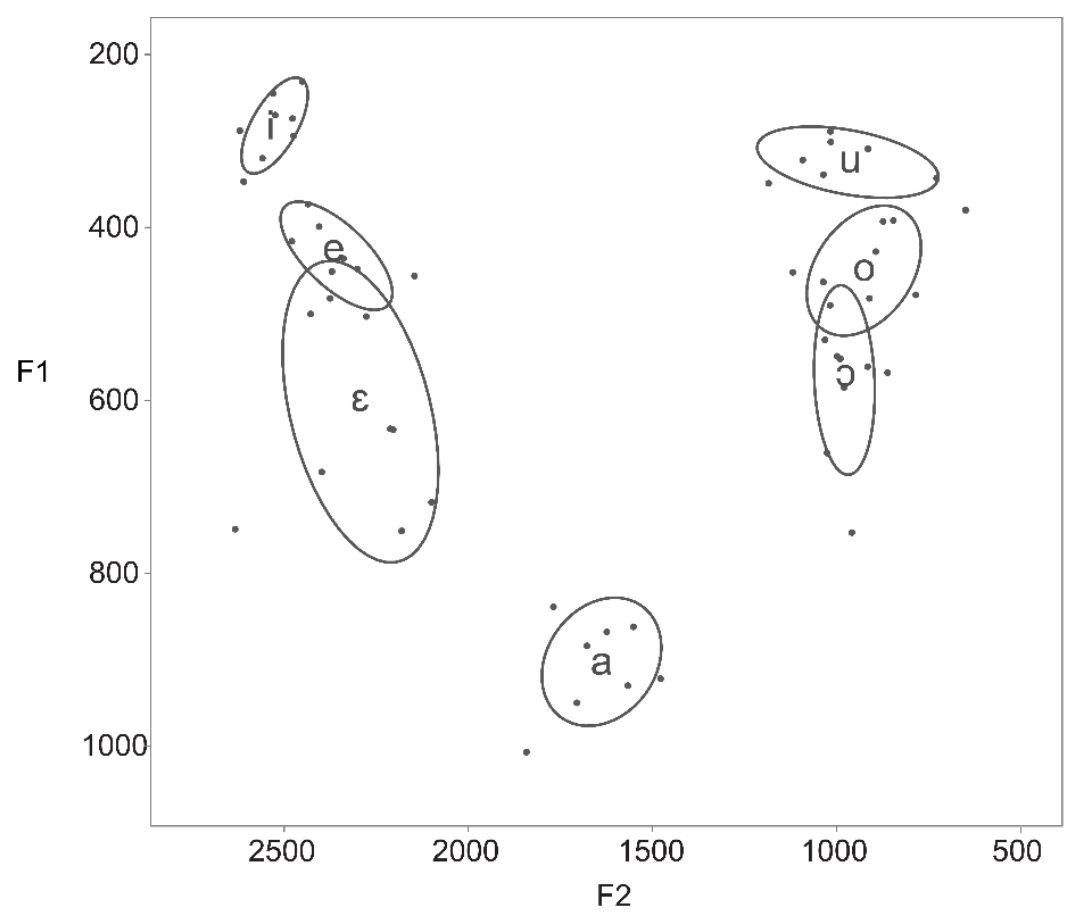

Figure 1: F1-F2 Vowel plot of surface vowel inventory (in $\mathrm{Hz}$, with $1 \mathrm{SD}$ ellipses)

\subsection{Labial harmony}

Tutrugbu words typically consist of a morphological root, and in nouns and verbs, at least one prefix. Suffixation is very restricted in the language, and no suffixes or enclitics undergo labial harmony. In nouns, only a single class-marking is allowed. Among verbs, though, a number of prefixes may be concatenated to the root. For this reason, the paper focuses on Tutrugbu verbs. The basic harmony pattern is demonstrated in (4)-(5). Here the second person pronouns trigger harmony on the prefixes /ba/ 'FUT' and /ka/ 'not.yet' We assume underlying /a/ in these forms because [a] surfaces when neither labial harmony nor ATR harmony apply, as in $(1 \mathrm{a}, \mathrm{b})$ and $(5 \mathrm{c}, \mathrm{d})$. These data illustrate two key aspects of labial harmony. First, [o] and [0] may not be followed by prefixes containing [e] or [a]. Second, this co-occurrence restriction applies only to prefixes, as root vowels are immune to harmony. ${ }^{4}$
a. o-bo- $\sqrt{\mathrm{e}}$
'2S-FUT-grow'
b. no-bo- $\sqrt{\mathrm{e}}$
'2P-FUT-grow'
c. e-be- $\sqrt{\mathrm{e}}$
'3S-FUT-grow'
d. be-be- $\int \overline{\mathrm{e}}$
'3P-FUT-grow'
e. o-bo-ji
'2S-FUT-appear'
f. no-bo-ji
'2P-FUT-appear'
g. e-be-ji
'3S-FUT-appear'
h. be-be-ji
'3P-FUT-appear'

\footnotetext{
${ }^{4}$ Throughout this paper the acute accent represents high tone, while the macron represents a mid tone. Low tone is unmarked. A potential fourth level tone, which is super high, is attested in some data. As for contour tones, the circumflex represents a falling tone (high-to-low), while the caron represents a rising tone (low-to-high). No other contour tones have been found to date.
} 

a. o-ko-bá
'2S-not.yet-come'
b. no-ko-bá
'2P-not.yet-come'
c. a-ka-bá
'3S-not.yet-come'
d. ba-ka-bá
'3P-not.yet-come'

In (6), 2S/P trigger rounding of a prefix with a long vowel, /zaa/ 'not.again.FUT' ${ }^{5} \operatorname{In}(7), 2 \mathrm{~s} / \mathrm{P}$ trigger harmony on two prefixes, /kaá/ 'still' and /ba/ 'VENT'. Thus, labial harmony targets both short and long vowels, and iterates throughout the entire pre-verbal domain.
a. jo-zoo-bá
'2S-not.again.FUT-come'
b. nó-zoo-bá
'2P-not.again.FUT-come'
c. á-zaa-bá
'3S-not.again.FUT-come'
d. bá-zaa-bá
'3P-not.again.FUT-come'
a. o-koó-bo-wu
'2S-still-VENT-climb'
b. no-koó-bo-wu
'2P-still-VENT-climb'
c. e-keé-be-wu
'3S-still-VENT-climb'
d. be-keé-be-wu
'3P-still-VENT-climb'

The previous examples showed only prefixes containing [-high] vowels. In $(8 a, b)$, the [+high] vowel of the negation prefix does not undergo harmony, unlike the [-high] prefixes seen in (4)-(7).
a. o-tí- $\sqrt{\mathrm{e}}$
*o-tú- Jẽ
'2S-NEG-grow'
b. no-tí- $\sqrt{\mathrm{e}} *$ no-tú- $\sqrt{\mathrm{e}}$
'2P-NEG-grow'
c. e-tí-Jè
'3S-NEG-grow'
d. be-tí- $\sqrt{\mathrm{e}}$
'3P-NEG-grow'

Furthermore, in (9) we see that [+high] prefixes are transparent to harmony. Harmony skips over NEG in $(9 \mathrm{a}, \mathrm{b})$ to trigger rounding on FUT.
a. o-tí-bo-wu
'2S-NEG-FUT-climb'
b. no-tí-bo-wu
'2P-NEG-FUT-climb'
c. e-tí-be-wu
'3S-NEG-FUT-climb'
d. be-tí-be-wu
'3P-NEG-FUT-climb'

At this point in the description it is important to recall the mismatches between the underlying and surface vowel inventories posited in (2). Specifically, two vowels exist in the underlying inventory that are absent from the surface inventory, $/ \varepsilon^{\mathrm{H}} \mathrm{o}^{\mathrm{H}}$. Despite the fact that these two vowels surface as mid vowels, they behave as high vowels in the language. In (9) above, the high vowel [i] is transparent to labial harmony. In (10) this same negation prefix surfaces as $\left[\mathrm{t}^{\prime}{ }^{\mathrm{H}}\right]$ before a [-ATR] root. Significantly, in both [ATR] contexts, the vowel of the negation prefix is transparent to labial harmony.
a. $\quad$-t $\dot{\varepsilon}^{\mathrm{H}}-\mathrm{bo}-\mathrm{bá}$
'2S-NEG-FUT-come'

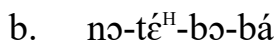
'2P-NEG-FUT-come'

Data in (8)-(10) demonstrate that [+high] vowels do not undergo labial harmony. In (11)-(12)we see that [+high] vowels also fail to initiate rounding. The first person plural prefix, which contains a [+hi, +rd] vowel, does not trigger rounding on a following [+high] vowel. In (11a,b), 1P surfaces as [bu] in conformity with regressive ATR harmony from the root. In $(11 \mathrm{c}, \mathrm{d})$ however, $1 \mathrm{P}$ surfaces as $\left[\mathrm{b} \mathrm{s}^{\mathrm{H}}\right]$, much like the alternation between $[i]$ and $\left[\varepsilon^{\mathrm{H}}\right]$ in the negation prefix in (8)-(10).

\footnotetext{
${ }^{5}$ This prefix includes a high tone that docks on the preceding vowel, thus the high tone on word-initial prefixes in (6).
} 
(11)
a. bu-tí-tī
'1P-NEG-know'
b. bu-tí-wu
'1P-NEG-climb'
c. $\quad b o^{\mathrm{H}}-\mathrm{t}^{\mathrm{H}}-\mathrm{bá}$
'1P-NEG-come'
d. $\quad b o^{\mathrm{H}}-t^{\prime} \varepsilon^{\mathrm{H}}-\mathrm{m} \supset$
'1P-NEG-See'

Moreover, 1P does not trigger labial harmony on a following [-high] vowel either, as seen in (12). Initialsyllable $\left[0^{\mathrm{H}}\right] \sim[\mathrm{u}]$ is followed by $[\mathrm{a}]$ rather than $[\mathrm{o}]$ or $[\mathrm{o}]$.
a. $\quad$ bo ${ }^{\mathrm{H}}$-ba-tī $\sim$ bu-ba-tī
'1P-FUT-know'
b. $\quad$ bo ${ }^{\mathrm{H}}$-ba-wu $\sim$ bu-ba-wu
'1P-FUT-climb'

To understand the data in (12), we must consider an important fact about ATR harmony in Tutrugbu. When preceded by an initial-syllable high vowel, the low vowel does not undergo regressive ATR harmony from the root. ${ }^{6}$ To date, Tutrugbu speakers have shown two patterns of low vowel neutrality in this context. For some speakers, [a] following an initial-syllable high vowel blocks ATR harmony while for others [a] is transparent. ${ }^{7}$

Thus far we have only observed harmony after $2 \mathrm{~S}$ and 2P. Observe in (13) that the class 3 subjectmarking prefix, SM3 /lo/, also triggers harmony on following non-high vowels. In (13a) as above, the high vowel of NEG is transparent, allowing harmony to skip over it. Other than $2 \mathrm{~S}$ and $2 \mathrm{P}, \mathrm{SM} 3$ is the only other $[-h i,+$ rd] prefix in the language. Since all three $[-h i,+$ rd] prefixes trigger harmony, we conclude that harmony is generally triggered by $[-\mathrm{hi},+\mathrm{rd}]$ prefixes.
a. o-ntí lo-tí-bo- $\int \overline{\mathrm{e}}$
b. o-hwi lo-goo-gagãlĩ
'CM3-hawk SM3-NEG-FUT-grow'
'CM3-rope SM3-no.longer-be.strong'

In (11-12), we saw that high round vowels, which alternate between $[\mathrm{u}] \sim\left[\mathrm{0}^{\mathrm{H}}\right]$, do not trigger labial harmony on a following vowel. This same behavior is mirrored in (14) below in the subject- and classmarking prefixes for class 8 . (The subject-marking prefix attaches to verbs while the class-marking prefix attaches to nouns.) CM8 surfaces as [bu] before [+ATR] roots, but as $\left[\mathrm{bs}^{\mathrm{H}}\right]$ before [-ATR] roots. SM8, like $1 \mathrm{P}$, does not trigger labial harmony on a following [-high] verbal prefix. Thus, the inertness of $1 \mathrm{P}$ as a trigger for labial harmony appears to be a more general inertness of all [+high] vowels.
a. bu-li bu-tí-Jè
b. $\quad$ bo ${ }^{\mathrm{H}}-\mathrm{wa} \quad$ bo ${ }^{\mathrm{H}}-\mathrm{ba}-\sqrt{\mathrm{e}} \sim \mathrm{bu}-\mathrm{ba}-\sqrt{\mathrm{e}}$
'CM8-palm.tree SM8-NEG-grow'
'CM8-grass SM8-FUT-grow'

In sum, $\left[\rho^{\mathrm{H}}\right]$ and $\left[\varepsilon^{\mathrm{H}}\right]$ pattern like the high vowels, $[\mathrm{u}]$ and $[\mathrm{i}]$. They do not trigger labial harmony, nor do they undergo labial harmony. Further evidence suggesting the essential [+high] character of these vowels comes from related Tafi (Bobuafor 2013). In Tafi, observe that the [+high] vowel [ $\mho$ ] does not trigger labial harmony on the [-high] [a] of the future prefix in (15b). In contrast, harmony obtains after the non-high vowel, [0], exemplified by $(15 \mathrm{c}, \mathrm{d})$.

Labial harmony in Tafi (Bobuafor 2013)
a. á-ba-vi '3S-FUT-go'
b. bú-ba-VI '1P-FUT-go'
c. ó-bo-vi '2S-FUT-go'
d. no-bo-dí '2P-VENT-look'
(ex. 97a, p. 42)
(ex. 4, p. 179)
(ex. 97b, p. 42)
(ex. 184, p. 396)

\footnotetext{
${ }^{6}$ For analyses of ATR harmony in Tutrugbu, see McCollum et al. (2019) and McCollum \& Essegbey (2018).

${ }^{7}$ One might wonder whether the bilabial stop blocks harmony in (11)-(12) because in the related language Nawuri, labialized consonants block regressive labial harmony (Casali 1995). But it is clear above that $\mathrm{FUT} / \mathrm{ba} / \mathrm{both}$ undergoes and spreads harmony, demonstrating that the place feature of the consonant has no bearing on harmony in Tutrugbu.
} 
The high vowels also fail to undergo harmony in Tafi, which is shown below. In $(16 a, b)$ the [-ATR] vowel [I] fails to undergo harmony from an initial round vowel, and in (16c,d), the [+ATR] vowel [i] shows the same neutrality to harmony. Finally, in (16e), harmony skips [I], showing that the [+high] vowels are also transparent in Tafi.

(16) High vowel neutrality in Tafi (Bobuafor 2013: 215)
a. bú-tí-b ${ }^{\mathrm{h}} \mathrm{ItT}$ ?
'1P-NEG-do'
b. j-tí-b ${ }^{\text {h }}$ ttī?
'2S-NEG-do'
c. bú-tí-hu?
'1P-NEG-hit'
d. ó-tí-hu?
'2S-NEG-hit'
e. ló-tí-zo-na
'3S.DEP-NEG-REP-eat' (ex. 38, p. 423)

The basic Tutrugbu facts laid out above are schematized in Table 1. Non-high vowels both trigger and undergo labial harmony, while high vowels do not participate in the harmony pattern at all, either as triggers or undergoers.

Table 1: Vowel height-based generalizations for labial harmony in Tutrugbu

\begin{tabular}{lll}
\hline vowel height & triggers labial harmony & undergoes labial harmony \\
\hline [+high] & $\times$ & $x$ \\
[-high] & $\checkmark$ & $\checkmark$ \\
\hline
\end{tabular}

Since high vowels are transparent to labial harmony, the pattern resembles labial harmony in Khalkha Mongolian (Svantesson 1985; see also Kaun 1995) and several Mbam languages of Cameroon (Boyd 2015).

\subsection{Harmony within roots}

In general, labial harmony operates on verbal prefixes, but a static co-occurrence restriction is also evident within roots. We compiled all the disyllabic verbs in our dictionary that have two non-high vowels. Of the 40 verb roots that met these criteria, 39 were harmonic for the feature [round], as shown in Table 2. One exception was found, /bolé/ 'throw.' Given the presence of only one exception, we interpret the data in Table 2 as evidence for a static restriction without any discernable directionality.

Table 2: Root co-occurrence of [-high] and [round]

\begin{tabular}{lll}
\hline Disyllable Type & Count & Examples \\
\hline$[+\mathrm{rd}][+\mathrm{rd}]$ & 9 & loks 'take', Jogo 'grow' \\
{$[-\mathrm{rd}][-\mathrm{rd}]$} & 30 & gbăna 'marry', béle 'finish' \\
[+rd] [-rd] & 1 & bolé 'throw' \\
[-rd] [+rd] & 0 & \\
\hline
\end{tabular}

Table 2 shows information about the distribution of [round] among non-high vowels in disyllabic roots. The distribution of the entire nine-vowel inventory in our database of disyllabic verb roots $(\mathrm{n}=112)$ is presented below, in Table 3. Unattested sequences are left blank. Note that the tendency across the inventory is for identical vowels in disyllabic verb roots. Vowel identity within roots requires agreement for [ATR], [round], and [high]. Agreement for the first two features relates directly to the two harmony patterns present in the language. The third, agreement for [high] relates to patterns elsewhere in the language, albeit more indirectly. Morpheme-specific height agreement occurs for the progressive prefix, to be discussed later, as well as the third-person object enclitic, which we do not discuss. In both morphemes, the height of some other position determines the height of these morphemes. Additionally, height restrictions play a role in both labial and ATR harmony. Labial harmony operates among non-high vowels only, and ATR harmony is also constrained by height, where disagreeing prefix height, in conjunction with a [+high] initial-syllable vowel, conditions low-vowel blocking (or for some speakers, transparency). In tandem with labial and ATR 
harmony, agreement for [high] within roots is likely a reflection of the activity of height agreement more generally operative within the language.

Table 3: Distribution of vowels in disyllabic verb roots

\begin{tabular}{lcccccccccr}
\hline $\mathrm{V} 1 \backslash \mathrm{V} 2$ & $\mathrm{a}$ & $\varepsilon$ & $\mathrm{e}$ & $\varepsilon^{\mathrm{H}}$ & $\mathrm{i}$ & 0 & $\mathrm{o}$ & $0^{\mathrm{H}}$ & $\mathrm{u}$ & Total \\
\hline $\mathrm{a}$ & 17 & & 2 & 12 & & & & & & 31 \\
$\varepsilon$ & & & & & & & & & & 0 \\
$\mathrm{e}$ & 1 & & 10 & & 4 & & & & 1 & 16 \\
$\varepsilon^{\mathrm{H}}$ & & & & 9 & & 4 & & & & 13 \\
$\mathrm{i}$ & & & 1 & 2 & 4 & & & & & 7 \\
0 & & & & 6 & 2 & 9 & & & 2 & 19 \\
$\mathrm{o}$ & & & 1 & & 2 & & 1 & & 5 & 9 \\
$\rho^{\mathrm{H}}$ & & & & & & & & & & 0 \\
$\mathrm{u}$ & 1 & & & & 2 & 2 & & & 12 & 17 \\
\hline Total & 19 & 0 & 14 & 29 & 14 & 15 & 1 & 0 & 20 & 112 \\
\hline
\end{tabular}

\subsection{Exceptional /ténú/}

Remember from the data above that roots do not undergo harmony from prefixes. There is one exception to this generalization. For some speakers, /ténú/ 'be able,' a loanword from Ewe, undergoes harmony. The first vowel of this word undergoes harmony just like non-high medial prefixes, as the examples in (17) demonstrate. In $(17 \mathrm{a}, \mathrm{b})$, the second person pronouns trigger harmony of both the FUT morpheme and the root. In $(17 \mathrm{c}, \mathrm{d})$, the third person pronouns undergo ATR harmony, and having no rounded vowels, play no triggering role in labial harmony.
a. o-bo-tónú
'2S-FUT-be.able'
b. no-bo-tónú
'2P-FUT-be.able'
c. e-be-ténú
'3S-FUT-be.able'
d. be-be-ténú
'3P-FUT-be.able'

There are two things to note about /ténú/. ${ }^{8}$ First, for some speakers /ténú/ does not undergo harmony. Second, for one speaker during data collection, this root consistently surfaced as /tónú/ regardless of preceding vowel quality. ${ }^{9}$

Tutrugbu is not the first language described with some pattern of prefix-initiated vowel harmony. However, in the languages cited as potential evidence for purely progressive harmony, like Tuki and Tunen (Mous 1986; Hyman 2002; Boyd 2015; Moskal 2015), prefix-initiated harmony is an exception, not the typical pattern in the language. In these languages, the sets of triggers and non-triggers are not distinguished by their phonological features, suggesting a morpheme-specific exceptionality-based account. Moreover, the morphemes that undergo prefix-initiated harmony in these languages are restricted to a small set of function words. Exceptional behavior is also found in Tutrugbu, but only as it relates to /ténú/. Generally, harmony in Tutrugbu is very regular, which distinguishes Tutrugbu from other languages with prefixinitiated vowel harmony. We will return to this point in the next section, further comparing languages with attested prefix-initiated patterns with Tutrugbu.

\footnotetext{
${ }^{8}$ We cannot conclusively rule out phonological teamwork in (17), from the root-final round vowel and the round prefix to trigger the rounding of /e/ to [o] (Lionnet 2016). No other disyllabic roots found thus far have the shape $\mathrm{CeCV}[\mathrm{rd}]$ or $\mathrm{CaCV}[\mathrm{rd}]$.

${ }^{9}$ In Tafi, /ténú/ is a prefix and not a root (Bobuafor 2013: 228-229).
} 


\subsection{Summary of harmony data}

A list of prefixes elicited, their allomorphs, and their participation in both ATR and labial harmony is shown below. In Table 4, we see the same generalizations presented throughout $\$ 2.2$. First, labial harmony is triggered by initial non-high prefixes and targets following non-high prefixes. Second, high vowels are transparent to labial harmony. Third and finally, labial harmony does not target roots.

Table 4: Verbal prefixes and their participation in vowel harmony

\begin{tabular}{|c|c|c|c|c|c|}
\hline Height & Gloss & $\begin{array}{l}\text { ATR } \\
\text { allomorphs }\end{array}$ & $\begin{array}{l}\text { Labial } \\
\text { allomorphs }\end{array}$ & Example & Gloss \\
\hline \multirow{9}{*}{ [-hi] } & FUT & ba, be & bo, bo & o-bo-bá & '2S-FUT-come' \\
\hline & not.yet & ka, ke & ko, ko & no-ko-bá & '2P-not.yet-come' \\
\hline & VENT & ba, be & bo, bo & o-koó-bo-ku & '2S-still-VENT-call' \\
\hline & still & kaá, keé & kəó, koó & o-koó-bo-ku & '2s-still-vent-call' \\
\hline & used.to & kaa, kee & kəə, koo & o-koo-tī & '2s-used.to-know' \\
\hline & not.again & gaa, gee & gəo, goo & lo-goo-gagãlĩ & 'SM3-not.again-be.strong' \\
\hline & not.again.FUT ${ }^{10}$ & zaa, zee & zoo, zoo & ó-Zつ॰-W $\tilde{\varepsilon}^{\mathrm{H}}$ & '2s-not.again.FUT-drink' \\
\hline & EXC & gblá, gblé & gbló, gbló & o-gbló-do & '2s-EXC-say’ \\
\hline & NEG.REP & gaa, gee & gəo, goo & o-goo-mo & '2S-NEG.REP-see' \\
\hline \multirow{5}{*}[+\text{hi}]{} & ITV & $\mathrm{d} \varepsilon^{\mathrm{H}}, \mathrm{di}$ & & o-di-wu & '2S-ITV-climb' \\
\hline & NEG & $\mathrm{t} \varepsilon^{\mathrm{H}}, \mathrm{t} \hat{i}^{\prime}$ & & o-t'́ $\varepsilon^{\mathrm{H}}-\mathrm{b} o-b a ́$ & '2s-NEG-FUT-come' \\
\hline & NEG.PST & $\mathrm{g} \varepsilon^{\mathrm{H}}, \mathrm{gi}$ & & n๑-g $\varepsilon^{\mathrm{H}}-\mathrm{bá}$ & '2P-NEG.PST-come' \\
\hline & PFV & $\mathrm{t} \varepsilon^{\mathrm{H}}, \mathrm{ti}$ & & o-t $\varepsilon^{\mathrm{H}}-\mathrm{b} \rho-w \tilde{\varepsilon}^{\mathrm{H}}$ & '2S-PFV-VENT-drink' \\
\hline & CONT & vléc ${ }^{\mathrm{H}}$, vlí & & o-vléc $\hat{c}^{\mathrm{H}}-\mathrm{b} \overline{\mathrm{a}}$ & '2s-CONT-come' \\
\hline \multirow[b]{2}{*}{ [ahi] } & PROG & á, é, $\varepsilon^{\mathrm{H}}, \dot{1}^{\prime}$ & ó, ó, jo $j^{\mathrm{H}}$ ú & o-tí-ó-wū & '2S-NEG-PROG-climb' \\
\hline & PROG.PST & $\begin{array}{l}\text { zaa, zee, } \\
\text { z } \varepsilon^{\mathrm{H}} \varepsilon^{\mathrm{H}}, \text { zii }\end{array}$ & zoo, zoo & o-zoo-bá & '2S-PROG.PST-come' \\
\hline
\end{tabular}

The next section relates the harmony pattern found in Tutrugbu to the issue of directionality and prominence as theoretical primitives. We lay out three general hypotheses concerning prominence and directionality, and compare a purely progressive account of labial harmony in Tutrugbu with a prominence-based account, discussing the divergent predictions of each analysis.

\section{Directionality and prominence}

The most pressing question at hand is what motivates harmony in Tutrugbu. In this section we lay out two options, purely progressive harmony and prominence-based harmony. We propose three diagnostics of directional vowel harmony, discussing how these distinguish between purely progressive and prominencebased harmony. Based on the evidence on hand, we suggest that prominence offers a more explanatorily adequate account of harmony in Tutrugbu than a purely progressive analysis. We move on from there to discuss genetic and typological evidence in favor of our prominence-based account.

\subsection{Theoretical background}

Two theoretical primitives have been proposed to account for the directional behavior in vowel harmony patterns - pure directionality and prominence. Purely directional harmony involves rightward or leftward harmony without respect to potential sources of prominence. Early generative models of harmony, by formal necessity, invoked purely directional propagation of the harmonic feature (e.g. Chomsky \& Halle

${ }^{10}$ This morpheme is also characterized by a high tone on the preceding vowel. 
1968; Johnson 1972; Jensen \& Stong-Jensen 1973; Vago 1973; Kenstowicz \& Kisseberth 1977; cf. Lightner 1965). However, much subsequent work recognized the importance of morphological prominence for the analysis of harmony (e.g. Clements 1976; Mohanan 1982; Goldsmith 1985; Kiparsky 1985; Baković 2000).

In the three subsections below we discuss three hypotheses concerning prominence and directionality - the strong prominence hypothesis, which treats all directionality as emergent; the weak prominence hypothesis, which treats all progressive directionality as emergent; and the purely directional hypothesis, which allows for both purely regressive and purely progressive directionality in harmony.

\subsubsection{Strong prominence hypothesis}

Bakovic (2000) asserts that the use of prominence in the analysis of vowel harmony obviates the need for directionality. We call this the strong prominence hypothesis. Baković writes:

If directionality were an independent assimilation parameter along which languages could arbitrarily differ, then one would expect to find at least the following two unattested vowel harmony patterns. The first is a left-to-right pattern from the initial syllable, root or prefix; the other is a right-to-left pattern from the final syllable, root or suffix.... A theory of assimilation with directionality as a theoretical primitive directly predicts the possibility of these kinds of unattested patterns. (2000: 7-8, emphasis ours)

As Baković makes clear, two types of languages would falsify his claim that directionality should be jettisoned in favor of prominence - purely progressive and purely regressive harmony. Problematically for Baković's claim, there are several attested cases of purely regressive harmony. For example, in Karajá (Ribeiro 2002), a Macro Jê language of Brazil, [+ATR] spreads leftward from any position in which it occurs, which is demonstrated below. In (18a), the leftmost vowel of the root, /duho/ 'curse', triggers leftward ATR harmony while the rightmost vowel of the root and all subsequent morphemes are unaffected. In $(18 \mathrm{~b}, \mathrm{c})$, though, a [+ATR] enclitic, triggers leftward harmony on roots as well as other underlying [-ATR] vowels. In (18c), an enclitic triggers leftward harmony while the word-final enclitic is unaffected.

Karajá ATR harmony (Ribeiro 2002: 482)

$\begin{array}{lll}\text { a. } / \emptyset \text {-r-o-duho=rerI/ } & \rightarrow & \begin{array}{l}\text { rotfu'horerI } \\ \text { *rotfu'horeri }\end{array} \\ \text { b. } / \emptyset \text {-r-o-duho=r-e/ } & \rightarrow & \text { rotfu'hore } \\ \text { c. } / \mathrm{b}-\varepsilon-d \varepsilon h \varepsilon=\mathrm{ikud} \mathrm{i}=\mathrm{h} \varepsilon / & \rightarrow & \text { bede'heikunih } \varepsilon\end{array}$

'3-CTFG-ANTI-curse=CTFG-PROG'

'3-CTFG-ANTI-curse $=$ CTFG-IMPERF'

'2-INTR-look=IMPF=EMPH'

In addition to Karajá, regressive harmony is reported in other languages, including Assamese and Bengali (Mahanta 2007), as well as Gua (Obiri-Yeboah \& Rose 2017). Given data from languages like Karajá and Assamese, it seems clear that the strong prominence hypothesis is incorrect. Since the strong prominence hypothesis does not predict languages like Karajá and Assamese, this suggests that some other force likely plays a role in the directionality of vowel harmony cross-linguistically.

\subsubsection{Weak prominence hypothesis}

Hyman $(2002,2008)$ proposes a weakened version of Baković's (2000) strong prominence hypothesis. Acknowledging cases of truly regressive harmony, Hyman suggests that vowel harmony may be motivated by prominence or directionality, but that directionality is necessarily regressive. In other words, the only theoretical primitives necessary to drive harmony are regressive directionality and prominence. Hyman marshals evidence from coarticulation and phrasal harmony to support his case that regressive harmony is a universal default setting for harmony. For coarticulation, it has been found that even in languages with progressive harmony, coarticulation tends to be anticipatory (Beddor \& Yavuz 1995; Conklin 2015, cf. Conklin \& Dimitrieva 2018). In languages with phrasal harmonies, like Nawuri (Casali 2002) and Kinande 
(Mutaka 1995; Archangeli \& Pulleyblank 2002), regressive phrasal harmony is far more extensive than its progressive counterpart.

Besides default regressive directionality, Hyman $(2002,2008)$ considers cases of morphological prominence, like root- or stem-control, to be possible sources for harmony. Harmony derived from the prominence of roots over affixes is widely attested and uncontroversial (Clements 1976; Kirchner 1993; Baković 2000). However, there are at least two other sources of prominence reported from the world's languages, metrical prominence and edge prominence. Since metrical prominence is not relevant for the analysis of Tutrugbu we do not discuss it (see Walker 2011; Kaplan 2015), and instead center our attention on edge prominence.

Barnes (2006) demonstrates that both edges of the word may exhibit privilege. Initial syllables are shown to host more contrasts and preserve contrasts more faithfully than other positions (Trubetzkoy 1969; Beckman 1998; Steriade 1994; Walker 2011; Kaplan 2015). Initial syllables are also argued to control hiatus resolution strategies in a number of languages (Casali 1997). Furthermore, initial syllables often resist lenition processes (Kirchner 2001; Becker et al. 2012, 2017).

For an example of initial-syllable prominence, consider the Esimbi data in (19) (Stallcup 1980; Hyman 1988; Walker 2011; Kaplan 2015). In Esimbi, only three vowel qualities are attested in roots, [i i u]. In the initial syllable, though, eight vowel qualities are attested. Walker (2011) and Kaplan (2015) analyze this as featural licensing, where [-high] is only licensed by the initial syllable. When [-high] is underlyingly affiliated with a stem vowel, it delinks and reassociates to the initial syllable to satisfy the licensing requirement, resulting in the pattern below. The initial syllable, which is always a prefix, can host all eight vowel qualities, while roots can only host three.

Esimbi height transfer

\begin{tabular}{|c|c|c|}
\hline underlying stem vowel & Infinitive & Gloss \\
\hline /i/ & u-ri & 'eat' \\
\hline b. $/ \mathrm{u} /$ & $\mathrm{u}-\mathrm{mu}$ & 'drink' \\
\hline c. $/ \mathrm{e} /$ & o-si & 'laugh' \\
\hline d. $/ \mathrm{o} /$ & o-mu & 'go up' \\
\hline /a/ & o-dzi & 'steal' \\
\hline f. $\quad / \varepsilon /$ & o-rini & 'be poor' \\
\hline g. $/ / 2 /$ & ó-mu & 'sit' \\
\hline h. /a/ & o-bi & 'come' \\
\hline
\end{tabular}

Like initial syllables, final syllables are also known to exhibit prominence. Final syllables are often lengthened, and host a larger variety of contour tones cross-linguistically (Zhang 2001). In truncated tokens of polysyllabic words, children have been shown to retain final as well as stressed syllables, over medial and unstressed syllables (Kehoe \& Stoel-Gammon 1997). Additionally, final vowels may also trigger assimilation. Hyman (2015) demonstrates that height harmony in Punu, a Bantu language of the Gabon, is triggered by the word-final syllable. Consider the data in (20). In (20a), all suffix vowels are underlyingly $/ \mathrm{a} /$, and are reduced to [ə] in the absence of harmony. In (20b), non-final suffix vowels are /i/ and maintain their quality before final /a/. In (20c), non-final suffix /a/ vowels all surface as [i] before the final /i/ of the present subjunctive suffix. Similarly, in (20e), non-final suffix /a/ vowels all surface as [u] before the final $/ \mathrm{u} /$ of the passive suffix. In $(20 \mathrm{~b}, \mathrm{~d})$, we see that non-final $/ \mathrm{i} /$ retains its quality before final $/ \mathrm{a} /$ or $/ \mathrm{i} /$, but in (20f), non-final $/ \mathrm{i} /$ vowels assimilate to final $/ \mathrm{u} /$ of the passive suffix. In these examples, the final syllable controls the realization of preceding suffixal /a/ and /i/ completely independent of root vowel quality.

(20) Final prominence in Punu harmony
a. /-bíng-as-an-a/
[-bíng-əs-ən-ə]
'roll (something)'
(general, "default" final/-a/)
b. /-bund-ig-il-a/
[-bund-iyil-ə] 'slander'
c. /-bíng-as-an-i/
[-bíng-is-in-i]
'roll (something)'
(present, subjunctive /-i/) 


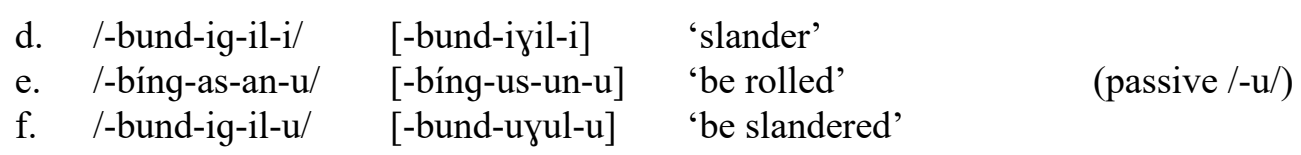

Final syllables also demonstrate prominence by resistance to assimilation. For instance, progressive height harmony and tonal spreading in Bantu often leave the final vowel unaffected (e.g. Hyman 1999: 238; Bickmore \& Doyle 1995; Bickmore 1996).

Walker (2011) and Kaplan (2015) expand Hyman's notion of prominence to include morphological, metrical, and edge prominence, resulting in four potential sources of prominence-triggered harmony: stems (typically, roots), stressed syllables, as well as initial and final syllables. If the weak prominence hypothesis is correct, then word-internal progressive harmony may only originate from morphological stems, stressed syllables, and initial syllables. ${ }^{11}$ Crucially, the weak prominence hypothesis predicts that progressive harmony may not be triggered by a position other than these prominent positions, in contrast to the regressive harmony seen in Karajá, which can be triggered from any position.

\subsubsection{Pure directionality hypothesis}

We argued above that the strong prominence hypothesis in Baković (2000) critically undergenerates since it cannot account for cases of purely regressive harmony that operate independent of any morphological, metrical, or edge prominence. The weak prominence hypothesis, then, admits the possibility of purely regressive directionality as a default setting that may occur in the absence of prominence-based harmony. If we assume that morphological roots, stressed syllables, and word edges may serve as prominent positions for harmony, then the type of pattern necessary to falsify the weak prominence hypothesis is prefix-initiated progressive harmony. Specifically, harmony that involves rightward spreading from any token of $[+\mathrm{F}]$, whether it be underlyingly affiliated with a prominent position or not, would counterexemplify the weak prominence claim, since under Hyman's proposal, harmony must either fall out from positional prominence or be regressive.

The pure directionality hypothesis differs from both Baković's and Hyman's proposals by stipulating directionality rather than deriving directional effects from other, independently necessary constraints in the grammar. Problematically, the pure directionality hypothesis does not attempt to answer why the harmony patterns attested in the world's languages typically originate at edges, roots, and other linguistically significant positions. We have suggested above that Baković's strong prominence hypothesis undergenerates, failing to account for purely regressive harmony in languages like Karajá and Assamese. However, the pure directionality account seems to vastly overgenerate, predicting harmony originating from any position within the word. That being said, if purely progressive harmony is attested, this would require simply stipulating directionality in a parametric fashion if not derivable from some independent facts about the language.

\subsection{Diagnostics of directionality}

To differentiate between prominence-based and purely directional harmony, we propose three general diagnostics of progressive vowel harmony in (21).

(21) Three diagnostics for progressive harmony

1. Does $[+\mathrm{F}]$ trigger left-to-right harmony?

2. Does $[+\mathrm{F}]$ occur in weak positions in the absence of $[+\mathrm{F}]$ in strong positions?

3 . When in weak positions, does $[+\mathrm{F}]$ trigger left-to-right harmony?

\footnotetext{
${ }^{11}$ We ignore potential progressive phrasal harmonies (e.g. where a word-final vowel could trigger harmony on a following word) simply due to a dearth of attested cases.
} 
First, the harmonic feature should spread from left to right. This is obvious, and does not require elaboration. Second, does the harmonic feature, $[+\mathrm{F}]$, occur in weak positions in the absence of $[+\mathrm{F}]$ in a strong position? In order to define strong and weak positions, it is first necessary to examine potential manifestations of prominence, like hiatus resolution, stress, and morphology, among others, to determine if certain positions exhibit privilege independent of the harmony pattern. To demonstrate purely progressive harmony, $[+\mathrm{F}]$ should occur in weak positions apart from harmony. One language that clearly passes our second diagnostic (in the regressive direction, of course) is Karajá. Recall from (18) that [+ATR] may occur anywhere in the word, and not just roots or word edges. Similarly, for clear evidence in favor of purely progressive harmony, the harmonic feature should occur in non-prominent positions independent of harmony.

Third, does the harmonic feature trigger rightward assimilation from all positions in which it occurs? In addition to occurring in weak positions, $[+\mathrm{F}]$ should also actually trigger harmony from those positions. For instance, McCollum \& Kavitskaya (2018) finds that labial harmony in Central Crimean Tatar is triggered by root-initial syllables, but not by the infinitive suffix even though it is invariantly [+round]. Thus, if $[+\mathrm{F}]$ occurs in weak positions independent of harmony, but only triggers harmony from prominent positions, this does not offer conclusive evidence in favor of a purely directional analysis. In the Crimean Tatar case, McCollum \& Kavitskaya's (2018) analysis requires harmony to originate in the prominent initial syllable. The best evidence for purely progressive harmony would come from cases where $[+\mathrm{F}]$ in weak positions triggers harmony on stronger (e.g. more morphologically interior, stressed) positions.

If the three diagnostics in (21) are adjusted for regressive harmony by reversing the direction of harmony, Karajá exemplifies all three. First, [+ATR] triggers leftward harmony, satisfying the first diagnostic. Second, [+ATR] occurs in weak positions in the absence of [+ATR] in strong positions, and third, [+ATR] triggers leftward harmony from weak positions. Other attested cases of purely regressive harmony, like Assamese and Gua similarly pass all three diagnostics, suggesting their general utility for defining purely directional harmony.

\subsection{Distinguishing between prominence-based and purely progressive harmony}

With these categories and diagnostics in mind, we must return to the most pressing question, though - how to analyze the pattern in Tutrugbu. Tutrugbu clearly passes our first diagnostic, since harmony propagates from left to right. As for our second and third diagnostics, since harmony is only triggered by initial positions, and we have no evidence to date for invariantly [+round] vowels in medial positions, we cannot definitely say what would happen if [+round] were to occur in a medial prefix in the absence of an initial [+round] vowel. Since we can only say with certainty that labial harmony is triggered by initial [+round] vowels, we cannot definitively distinguish between the prominence-based and purely progressive accounts of harmony in the language. If appropriate medial prefixes were found, however, it should be straightforward to distinguish between the two, and in Table 5, we outline the predictions of each analysis. If [+round] triggers harmony from initial positions, the prominence-based and purely progressive analyses converge on a shared prediction, rightward harmony, as schematized in (A) and (G). The two analyses differ, though, when [+round] occurs in non-initial positions independent of harmony. In such a case, the prominence-based account predicts that progressive harmony will not occur and that one of five possibilities will occur. First, as in Crimean Tatar (McCollum \& Kavitskaya 2015), the non-initial vowel may not trigger harmony at all, as in (B). Second, if all [+round] vowels must affiliate with the initial syllable as a licensing requirement, then the presence of [+round] in V2 could trigger regressive harmony on the initial syllable, as in (C); see Kaplan (2015). Second, the language could also exhibit bidirectional harmony to all prefixes, and both affiliate the [+round] feature with the initial prefix and all subsequent prefixes, as in (D). Alternatively, a language could repair this structure by unrounding or deleting the potential trigger and thus escaping the harmonic imperative, as exemplified by (E) and (F). These possibilities are distinct from the prediction from the purely progressive account. If [+round] occurs in a non-initial position independent of harmony, the purely progressive account predicts that [+round] will spread rightward, as seen in $(\mathrm{H})$. 
Table 5: Predictions of prominence-based and purely progressive analyses

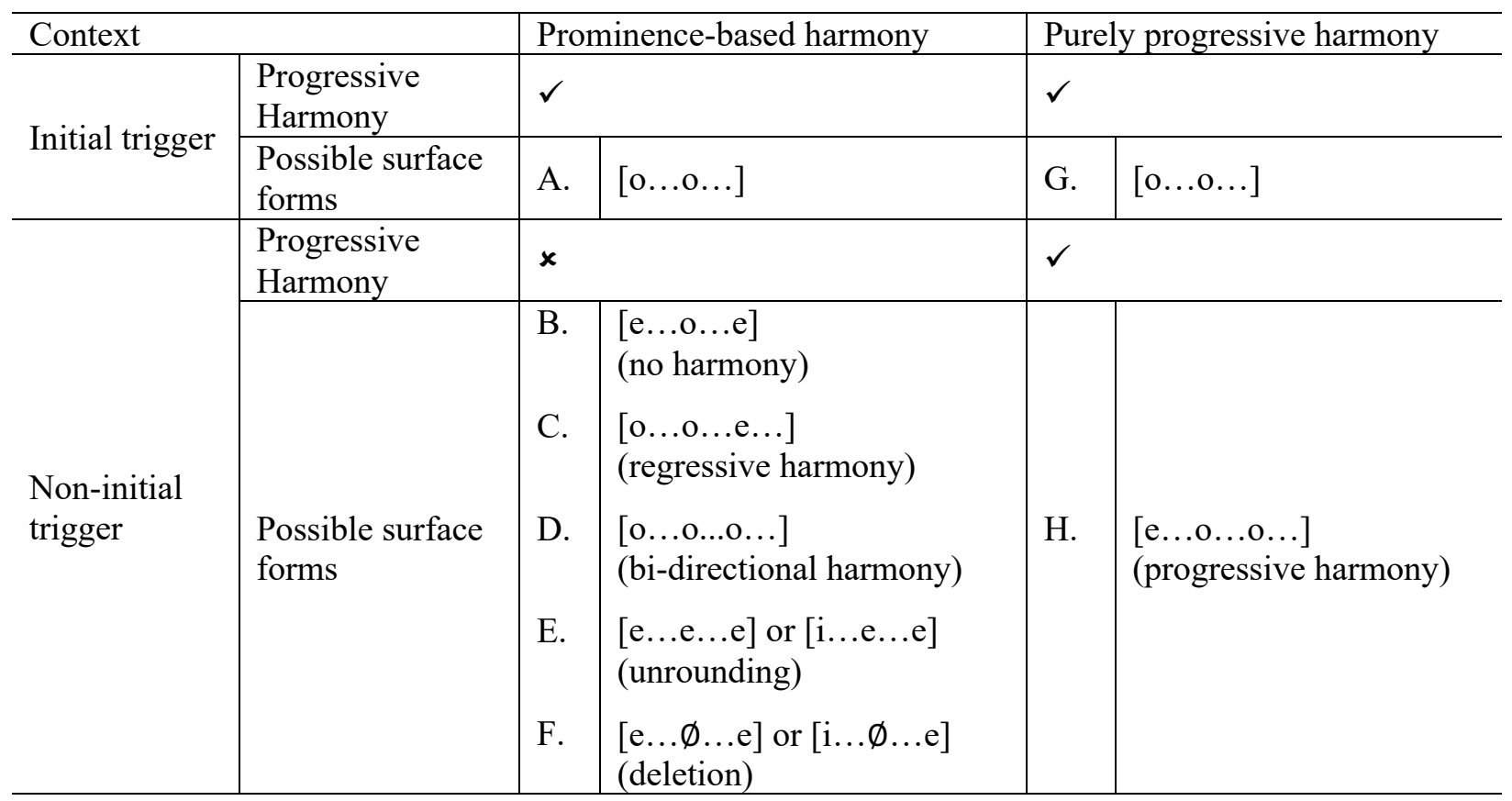

As detailed in the previous section, the only contexts found in the data involve harmony from an initialsyllable trigger. As such, the prominence-based harmony and purely progressive harmony analyses are not clearly distinguishable based on this data alone. That being said, there is still evidence available to decide between the two analyses. First, the fact that roots fail to undergo harmony suggests that prominence plays a role in the pattern. If not, then we would expect harmony to trigger alternations on both medial prefixes and roots. Second, if harmony is prominence-based, this predicts that initial syllables should exhibit some signs of privilege distinct from the harmony pattern. Also, if harmony is purely progressive, then the absence of invariantly [+round] medial prefixes must be construed as an accidental gap. If harmony in Tutrugbu is prominence-based, the absence of medial [+round] prefixes is not necessarily a problem. If harmony among prefixes is controlled by the initial syllable and both values of the feature spread (cf. Steriade 1995), then the absence of invariantly [+round] medial prefixes receives an explanation. Stated differently, if the initial syllable is [-round], then it could spread its [-round] feature to all medial prefixes, thereby unrounding prefixes that are underlyingly [+round] (see Hyman 2002 for a potential example of [-round] spreading). There are several ways to address these predictions, and the rest of this section is devoted to determining whether the initial syllable is really prominent in the language and whether the lack of invariantly [+round] prefixes is likely to be an accident.

\subsubsection{Contrast licensing}

If the initial syllable is prominent, then it should be privileged relative to other syllables in the word. One piece of evidence that suggests that initial syllables are privileged comes from contrast licensing. If we assume that the nine surface vowels in Tafi correspond to the historical Tutrugbu vowel system, then roots allow all nine contrasts, as $[\varepsilon]$ and $\left[\varepsilon^{\mathrm{H}}\right]$, as well as $[0]$ and $\left[0^{\mathrm{H}}\right]$ may occur in roots. This is demonstrated by

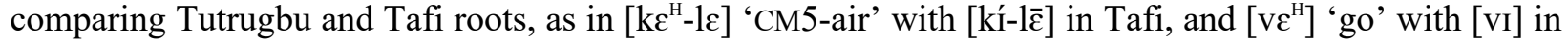
Tafi. In initial prefixes, four underlying vowel qualities are permitted $/ a \rho \varepsilon^{\mathrm{H}} \rho^{\mathrm{H}}$, and due to ATR harmony from the root, eight vowels may occur on the surface. Medial prefixes may host only two vowel qualities underlyingly, $/ \mathrm{a} \varepsilon^{\mathrm{H}} /$, as both [+ATR] and [+round] may only occur due to harmony. Lastly, suffixes can only host $/ \mathrm{a} \varepsilon^{\mathrm{H}} /$, and since neither ATR nor labial harmony affect suffixes, only these two vowels may 
surface. Contrast licensing by position is shown in Table 6 below. Permissible underlying vowel qualities are shown on the left, and attested surfaces qualities are shown on the right

Table 6: Underlying and surface vowel distribution by position

\begin{tabular}{ccccccccc}
\hline & \multicolumn{9}{c}{ Underlying } \\
\cline { 2 - 8 } Vowel & Roots & $\begin{array}{c}\text { Initial } \\
\text { prefixes }\end{array}$ & $\begin{array}{c}\text { Medial } \\
\text { prefixes }\end{array}$ & Suffixes & Roots & $\begin{array}{c}\text { Initial } \\
\text { prefixes }\end{array}$ & $\begin{array}{c}\text { Medial } \\
\text { prefixes }\end{array}$ & Suffixes \\
\hline a & $\checkmark$ & $\checkmark$ & $\checkmark$ & $\checkmark$ & $\checkmark$ & $\checkmark$ & $\checkmark$ & $\checkmark$ \\
$\varepsilon^{\mathrm{H}}$ & $\checkmark$ & $\checkmark$ & $\checkmark$ & $\checkmark$ & $\checkmark$ & $\checkmark$ & $\checkmark$ & $\checkmark$ \\
0 & $\checkmark$ & $\checkmark$ & & & $\checkmark$ & $\checkmark$ & $\checkmark$ & \\
$0^{\mathrm{H}}$ & $\checkmark$ & $\checkmark$ & & & $\checkmark$ & $\checkmark$ & \\
$\mathrm{e}$ & $\checkmark$ & & & $\checkmark$ & $\checkmark$ & $\checkmark$ \\
$\mathrm{i}$ & $\checkmark$ & & & $\checkmark$ & $\checkmark$ & $\checkmark$ & \\
$\mathrm{o}$ & $\checkmark$ & & & $\checkmark$ & $\checkmark$ & $\checkmark$ & \\
$\mathrm{u}$ & $\checkmark$ & & & & $\checkmark$ & $\checkmark$ & & \\
$\varepsilon$ & $\checkmark$ & & & & $\checkmark$ & & & \\
\hline
\end{tabular}

\subsubsection{Hiatus resolution}

A second piece of evidence for the privilege of initial syllables comes from hiatus resolution. Vowel-vowel sequences across word boundaries are resolved via the reduction of the initial vowel, as demonstrated in (22) below. As seen there, V1 is reduced to a glide when it is a front or round vowel (22a-d), but deleted when V1 is /a/ (22e,f). ${ }^{12}$ Bobuafor (2013: 40) and Schuh (1995: 47-56) note similar patterns for Tafi and Avatime.

(22) Hiatus resolution across word boundaries

\section{Example}

a. $\mathrm{Ci} \mathrm{o} \rightarrow \mathrm{Cio}_{\mathrm{o}}$ /e-dí o-si no/ $\rightarrow$ [edjósi no]

b. $\mathrm{Ci} \mathrm{a} \rightarrow \mathrm{Cja}^{j} \quad$ le-dí a-gbe no/ $\rightarrow$ [edjágbe no]

c. Co a $\rightarrow \mathrm{C}^{\mathrm{w}} \mathrm{a} \quad$ /a-mó a-dõ no/ $\rightarrow$ [amwádõ no]

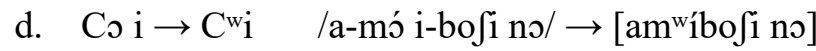

e. $\mathrm{Ca} \mathrm{e} \rightarrow \mathrm{Ce} \quad$ /a-na e-li no/ $\rightarrow$ [ayeli no]

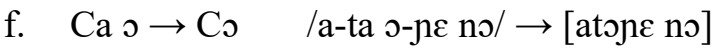

Gloss

3S-look.at CM3-tree DEF 3S-look.at CM1plate DEF 3S-see CM1-squirrel DEF

3S-see CM4-sheep

DEF

3S-eat CM1palm.fruit DEF 3s-kick CM3firewood DEF
Translation

"S/he looked at the tree."

"S/he looked at the plate."

"S/he saw the squirrel."

"S/he saw the sheep."

"S/he ate the palm

fruit."

"S/he kicked the firewood."

Word-internally, the strategy for hiatus resolution depends on position. When V1 is non-initial, V1 is reduced, like in (22) above. In (23a,b), the negation prefix is reduced immediately before the onsetless progressive prefix. In $(23 \mathrm{c}, \mathrm{d})$, the root vowel is reduced before the onsetless third-person object suffix.
a. a-tét $\varepsilon^{\mathrm{H}}$-á-bá
[atábā]
'3S-NEG-PROG-come'
b. o-tí-ó-tsí
[otiótsī]
'2S-NEG-PROG-crawl'

${ }^{12}$ Compensatory lengthening appears to optionally apply when /a/ is deleted. 

c. a-baka- $\dot{\varepsilon}^{\mathrm{H}}$
[abak $\left.\varepsilon^{\mathrm{H}}\right]$
'3S-ask-3S.OBJ'
d. a-mó- $\dot{\varepsilon}^{\mathrm{H}}$
$\left[\mathrm{am}^{\mathrm{w}} \dot{\varepsilon}^{\mathrm{H}}\right]$
'3S-see-3S.OBJ'

When V1 of a VV sequence is in the initial syllable, however, V1 is not reduced. In these contexts, V2 assimilates to V1. To see this, first observe the realization of the progressive prefix. The progressive prefix is underlyingly $/ \varepsilon^{\mathrm{H}} /$ but assimilates in height to the initial-syllable vowel. In (24a-d), PROG surfaces as a high vowel that, like other prefixes, agrees with the root for [ATR]. Note that since the two adjacent vowel qualities are identical in these cases, there is no reduction of NEG. In (24e-f), PROG is [-high], like the initial prefix. Lowered PROG is subject to labial harmony from the initial prefix in addition to ATR harmony from the root. As a result of these three processes, PROG surfaces as a copy of the initial prefix. Since in (24e-f), the vowel quality of PROG is not identical to NEG, NEG reduces.
a. $\quad \varepsilon-\mathrm{t}^{\mathrm{H}}-\hat{\varepsilon}^{\mathrm{H}}-\mathrm{b} \bar{a}$
'1S-NEG-PROG-come'
b. i-tí-í-wū
c. bo-té ${ }^{\mathrm{H}}-\dot{\varepsilon}^{\mathrm{H}}-\mathrm{b} \overline{\mathrm{a}}$
'1S-NEG-PROG-climb'
d. bu-tí-1́-wū
'1P-NEG-PROG-come'
e. $a-t^{\prime} \varepsilon^{H}-a ́-b \bar{a}$
'1P-NEG-PROG-climb'
f. e-tí-é-wū
[atiábā]
'3S-NEG-PROG-come'
g. o-t t' $\hat{\varepsilon}^{\mathrm{H}}-\mathrm{o}-\mathrm{b} \bar{a}$
[etiéwū]
'3S-NEG-PROG-climb'
h. o-tí-ó-wū
[otíbāa]
'2S-NEG-PROG-come'
[otiówū]
'2S-NEG-PROG-climb'

The only context where the initial-syllable vowel may be V1 in a VV sequence is when the initial-syllable prefix is immediately followed by the progressive prefix. In these cases, the realization of PROG after the $\left[+\right.$ hi, + rd] vowels $/ \mathrm{s}^{\mathrm{H}} \mathrm{u} /$ is most critical, $(25 \mathrm{c}, \mathrm{d})$. Here, sequences of $/ \mathrm{o}^{\mathrm{H}}-\varepsilon^{\mathrm{H}} /$ and $/ \mathrm{u}-\mathrm{i} /$ are repaired by assimilating V2 to V1. These are the only instances where distinct vowel qualities may occur in this context, and in these cases V1 is preserved.
a. $\varepsilon^{\mathrm{H}}-\hat{\varepsilon}^{\mathrm{H}}-\mathrm{b} \bar{a}$
b. i-í-wū
c. bo- $\varepsilon^{\mathrm{H}}-\mathrm{b} \bar{a}$
d. bu-í-wū
e. a-á-bā
f. e-é-wū
g. o-ó-bā
h. o-ó-wū

[boóbā]

[buúwū]

'1S-NEG-PROG-come'
'1S-NEG-PROG-climb'
'1P-NEG-PROG-come'
'1P-NEG-PROG-climb'

$\begin{array}{ll} & \text { '1S-NEG-PROG-come' } \\ \text { [bośbā] } 1 \text { S-NEG-PROG-climb' } & \text { '1 } 1 \text {-NEG-PROG-come' } \\ \text { [buúwū] } & \text { '1P-NEG-PROG-climb' } \\ & \text { '3S-NEG-PROG-come' } \\ & \text { '3S-NEG-PROG-climb' } \\ & \text { '2S-NEG-PROG-come' } \\ \text { '2S-NEG-PROG-climb' }\end{array}$

As we saw in (22-(25), reduction of V1 is the general pattern in the language, found across word boundaries as well as word-internally. However, V2 is reduced when V1 is in the initial syllable. Based on this and the relatively large number of contrasts that the initial syllable can host, we conclude that the initial syllable in Tutrugbu is phonologically prominent. As a result, we conjecture at this point that harmony is motivated by prominence.

\subsection{The absence of medial [+round] prefixes}

In addition to the putative prominence of initial syllables, the lack of medial [ + round] prefixes offers another way to distinguish between the two analyses at hand. Here we discuss both language-internal and typological evidence related to the distribution of [round] on initial and medial prefixes.

\subsubsection{Language-internal statistical probability}

If the lack of medial [+round] prefixes in Tutrugbu is purely accidental, this predicts that there is no relationship between position and the occurrence of invariantly round prefixes. To test this, we counted the 
number of morphemes found during fieldwork that occur in initial and medial prefix positions. In total, we found 24 initial prefixes (6 pronominal subject prefixes, 9 noun class-marking prefixes, and 9 subject agreement prefixes). Of these, 7 are invariantly round ( 3 pronominal subject prefixes, 2 noun class prefixes, and 2 agreement prefixes). Of the 16 medial prefixes found in the language, none are invariantly round. Among the non-high medial prefixes, all alternate in accordance with harmony; among the high prefixes, all are invariantly unrounded. Using a Fisher's exact test, the distribution of [round] is not independent of position, $p=.03$. In other words, there is a significant relationship between prefix position and [round].

Table 7: The distribution of [round] in initial versus medial prefixes

\begin{tabular}{llll}
\hline & Initial & Medial & Total \\
\hline$[-$ round] & 17 & 16 & 33 \\
{$[+$ round] } & 7 & 0 & 7 \\
\hline Total & 24 & 16 & 40 \\
\hline
\end{tabular}

This result is not conclusive proof that round vowels on medial prefixes are licensed only by harmony. Instead, this result provides suggestive evidence that the distribution of round vowels in prefixes is not accidental.

\subsubsection{Medial prefixes in the typology of prefix-initiated harmony}

In addition to language-internal evidence, the distribution of round vowels in other Ghana-Togo Mountain languages, as well the distribution of harmony-triggering vowels in other languages with prefix-initiated harmony, offer another way to evaluate the lack of invariantly round medial prefixes in Tutrugbu.

We have access to grammars of twelve other Ghana-Togo Mountain languages, which are shown in Table 8 below. In three of these languages, Tafi, Logba and Igo, labial harmony is triggered by the initial prefix, and round prefixes do not occur apart from harmony. In Tuwuli and Akebu, labial harmony is triggered by the root, and spreads regressively throughout the prefixal domain. In both of these languages, a round prefix may only occur in the presence of a round root. In contrast, in all seven Ghana-Togo Mountain languages that do not exhibit some form of labial harmony, invariantly round medial prefixes are attested. In languages with harmony, medial prefixes may be round only in the presence of a round vowel in a prominent position. Elsewhere in the language family, though, invariantly round medial prefixes are attested regardless of root or initial vowel quality.

Table 8: Labial harmony and [+round] medial prefixes in the Ghana-Togo Mountain languages

\begin{tabular}{|c|c|c|c|c|c|}
\hline Language & $\begin{array}{l}\text { labial } \\
\text { harmony }\end{array}$ & $\begin{array}{l}{[+ \text { round }]} \\
\text { medial prefixes }\end{array}$ & Example & Gloss & Citation \\
\hline Tafi & $\begin{array}{l}\text { yes, } \\
\text { from V1 }\end{array}$ & $\begin{array}{l}\text { only due to } \\
\text { harmony }\end{array}$ & ó-bo-tã & '2s-FUT-eat' & $\begin{array}{l}\text { Bobuafor (2013: } 32, \\
42-43)\end{array}$ \\
\hline Logba & $\begin{array}{l}\text { yes, } \\
\text { from V1 }\end{array}$ & $\begin{array}{l}\text { only due to } \\
\text { harmony }\end{array}$ & ó-bó-kpe & 'SM-FUT-eat' & Dorvlo (2008: 144-146) \\
\hline Igo & $\begin{array}{l}\text { yes, } \\
\text { from V1 }\end{array}$ & $\begin{array}{l}\text { only due to } \\
\text { harmony }\end{array}$ & o-no-zo-fo-nò & $\begin{array}{l}\text { '2-HAB-PST- } \\
\text { AUX-weave' }\end{array}$ & Gblem-Podi (1996) \\
\hline Tuwuli & $\begin{array}{l}\text { yes, } \\
\text { from root }\end{array}$ & $\begin{array}{l}\text { only due to } \\
\text { harmony }\end{array}$ & so-mo & 'CM-neck' & Harley (2005: 64) \\
\hline Akebu & $\begin{array}{l}\text { yes, } \\
\text { from root }\end{array}$ & $\begin{array}{l}\text { only due to } \\
\text { harmony }\end{array}$ & lóó-pò-kó & ‘3S-FUT-go’ & $\begin{array}{l}\text { Makeeva \& Shluinskij } \\
\text { (2013: 363) }\end{array}$ \\
\hline Avatime & no & yes & kíà-zǒ-ta & '1P-REP-eat' & $\begin{array}{l}\text { Defina }(2016: 56,61) \\
\text { van Putten }(2014: 53)\end{array}$ \\
\hline
\end{tabular}




\begin{tabular}{llllll}
\hline Anii & no & yes & gí-bònà-dá & '1P-PST-be’ & Morton (p.c., 2002) \\
Buem & no & yes & & & Allan (1974) \\
Ikposo & no & yes & á-fònǎ-fósó & '3s-HAB-seek' & Soubrier (2013: 206-207) \\
Likpe & no & yes & è-bó-kpé & '2S-FUT-put' & Delalorm (2016: 328-329) \\
Sclec & no & yes & a-too-wola & '3s-PFV-carve' & Agbetsoamedo (2014: 24) \\
Siwu & no & yes & à-ò-na & '2S-PFV-see' & Dingemanse (2011: 320) \\
\hline
\end{tabular}

If one claims that the absence of invariantly round vowels in medial prefixes is accidental in Tutrugbu, their absence in all other related languages with vowel harmony, and their presence in languages without harmony must be construed as accidental, too. This seems highly unlikely, and we interpret these facts from the language family as further evidence in favor of a prominence-based interpretation of harmony in Tutrugbu.

In addition to language-internal and genetic evidence, we examined unrelated languages with prefixinitiated harmony patterns to determine if the distribution of the harmonic feature, $[+\mathrm{F}]$, is independent of position. We know of five prefix-initiated labial harmony patterns outside the Ghana-Togo Mountain languages - one Kwa language, Nkami (Akanlig-Pare \& Asante 2016), and four Bantu languages of Cameroon, Abo (Atindogbe 1996; Finley 2012), Gunu, Maande, and Mmala (Boyd 2015: 251-253). As in Tutrugbu, [+round] medial prefixes may only occur due to harmony in these languages. Thus, none of these languages present the evidence necessary to satisfy our second and third diagnostics, since [+round] does not occur in weak positions independent of harmony.

We also know of four prefix-initiated ATR harmony patterns: Tunen, Tuki, KiBudu, and Kinande (Mous 1986; Kutsch Lojenga 1994; Hyman 2002; Boyd 2015; Moskal 2015). We present data from Tunen below that is representative of these five languages. In Tunen, a Mbam language of Cameroon, prefixes generally alternate based on the [ATR] value of the root, as shown in (26) (Dugast 1971; Mous 1986; van der Hulst et al. 1986; Boyd 2015; Moskal 2015). In these examples, the class 3 and 4 suffixes agree with the nominal root for [ATR]. However, function words behave differently than content words. In (27a-e), we see the function words, /táná/ 'this', /mòtí/ 'one/some,' and /fàn dì/ 'two', surface as [-ATR] when preceded by [-ATR] prefixes. However, in (27f-j), we see these same function words surfacing as [tónó] 'this', [mòtí] 'one/some', and [fàn dí] 'two' after [+ATR] prefixes. Thus, in (27) these roots alternate based on the $[\mathrm{ATR}]$ value of the prefix. This prefix-initiated progressive harmony in Tunen is limited to function words only. When the root is a content word, harmony is regressive.

Regressive ATR harmony in Tunen
a. mò-líní 'CM3-tail'
b. mù-lón dù 'CM3-tendril'
c. mì-líní 'CM4-tail'
d. mì-lán dù 'CM4-tendril'

(27) Progressive ATR harmony in Tunen
a. mó-táná 'CM1-this'
b. j̀-mòtí 'CM1-one/some'
c. pá-táná 'CM2-this'
d. pá-mòtí 'CM2-one/some'
e. pá-fàndì 'CM2-two'
f. mú-tóná
g. ú-mòtí
h. mí-tóná
i. í-mòtí
j. í-fว̀ndí
'CM3-this'
'CM3-one/some'
'CM4-this'
'CM4-one/some'
'CM4-two'

Using our three diagnostics above, let us consider progressive ATR harmony in Tunen. First, does harmony spread from left to right? Yes. Second, does [+ATR] occur in weak positions apart from harmony? The feature value $[+\mathrm{ATR}]$ occurs in prefixes, roots, and suffixes in the language. However, the only prefixes 
that are invariantly [+ATR] are initial prefixes, like in $(27 \mathrm{f}-\mathrm{j})$. There are no invariantly $[+\mathrm{ATR}]$ prefixes that occur word-medially. Therefore, we cannot conclusively say that [+ATR] occurs in weak positions apart from harmony. According to Boyd (2015), there are two [+ATR] dominant suffixes, and otherwise [+ATR] occurs only in roots or initial syllables. As for our third diagnostic, when in weak positions, does [+ATR] trigger left-to-right harmony? Since [+ATR] does not occur in any obviously weak positions, we cannot say with certainty that this harmony satisfies our third diagnostic. In sum, the results from Tunen are unclear. The language does not provide the contexts necessary to fully judge whether progressive harmony is prominence-based or purely progressive.

More generally, in all of these languages, a single prefix may trigger [+ATR] spreading on certain function words. Notably absent, though, are medial prefixes in these languages. We know of one additional prefix-initiated harmony, height harmony in Mmala (Boyd 2015: 253-254). Just like the prefix-initiated ATR harmony patterns, though, only a single prefix may occur in the Mmala pattern, and so there is no evidence for a purely progressive analysis.

In sum, we find no evidence of medial prefixes that may invariantly bear the harmonic feature for any of the prefix-initiated harmony patterns examined. Among the ATR and height harmony patterns, this was due to the lack of medial prefixes. However, in the nine languages that exhibit labial harmony from the initial prefix, invariantly round medial prefixes are unattested. If the lack of round medial prefixes in Tutrugbu is accidental, we should not expect any necessary relationship between prefix-initiated harmony and invariantly round medial prefixes. Yet, this is not what we have found. Instead, we have found a significant relationship between prefix-initiated harmony and medial prefixes. In languages with harmony, medial round prefixes do not occur, but in languages without prefix-initiated labial harmony, invariantly round medial prefixes may occur. In one language, this sort of gap could be accidental. Perhaps even within the language family this could be accidental, although less likely. However, given that every language with prefix-initiated harmony, regardless of genetic affiliation and harmonic feature, exhibits the same lack of invariantly $[+\mathrm{F}]$ medial prefixes suggests a more principled reason for this gap.

Taken together, all the evidence discussed in this section supports a prominence-based analysis. Initial syllables exhibit privilege in the language, as manifested in hiatus resolution and contrast licensing. Furthermore, given the number of morphemes discovered during fieldwork, the lack of medial [+round] prefixes is statistically significant. Within the language family, the fact that every language with harmony exhibits the same prohibition on medial [+round] prefixes, while every language without harmony allows them, provides even more evidence that invariantly [+round] prefixes are not accidentally absent in medial prefixes. Finally, the same absence of medial $[+\mathrm{F}]$ prefixes in all other languages with prefix-initiated harmony further reinforces the generalization - prefix-initiated progressive harmony may be triggered by initial syllables only.

Before moving onto the Optimality Theoretic analysis, we want to reiterate that the proposed analysis is not the only possible analysis of the data. It is possible, as noted throughout, to construct an analysis that relies of progressive directionality without regard for prominence. The challenge for this analysis is accounting for the lack of [+round] medial prefixes in Tutrugbu, and more generally, the lack of [+F] medial prefixes in other languages with similar harmony patterns. Based on the data at hand, we argue that progressive directionality in Tutrugbu falls out from prominence, and by extension, that progressive directionality is more generally derivable from prominence. In other words, progressive directionality is epiphenomenal (see also Kaplan 2008).

\section{Formal analysis}

In this section we present an analysis of labial harmony in Tutrugbu using Agreement-by-Correspondence (ABC; Rose \& Walker 2004; Hansson 2010; Bennett 2015 a.o.). As a reminder of the data shown in $\$ 2$, labial harmony in Tutrugbu exhibits the following four properties. It is triggered by the initial syllable. It is definable in terms of vowel height, both for triggers and targets. The domain of harmony is definable in 
terms of morphological constituency, since harmony is almost exclusively limited to prefixes. Finally, within roots harmony holds as a co-occurrence constraint without any discernible directionality.

$\mathrm{ABC}$ was developed to account for similarity-sensitivity and transparency in consonant harmony. Both similarity and transparency are crucial to the analysis presented below, making ABC a good fit for the analysis of Tutrugbu presented below. Note that for the formalization of harmony, we ignore ATR harmony (see McCollum \& Essegbey 2018 for an OT analysis, and McCollum et al. 2019 for a computational analysis).

$\mathrm{ABC}$ uses two mechanisms to drive harmony, surface correspondence and surface identity. CORR constraints enforce correspondence between vowels that are featurally similar, which is indicated by subscript indices throughout. Thus, correspondence preferentially targets segments with more shared features. Since labial harmony in Tutrugbu is triggered by and targets non-high vowels only, the feature [-high] will play a key role in the analysis. In (28) we define CORR-[-HI], which drives same-height correspondence among non-high vowels.

$$
\text { CORR-[-HI] }
$$

Let $\mathrm{S}$ be an output string of segments, and let $\mathrm{X}$ and $\mathrm{Y}$ be vowels in $\mathrm{S}$ with the feature [-high]. Assign a violation if $\mathrm{X}$ and $\mathrm{Y}$ do not correspond.

The CORR constraint above, CORR-[-HI], encodes two cross-linguistic generalizations regarding labial harmony made in Kaun $(1995,2004)$. First, non-high vowels are better triggers for harmony than high vowels, and second, same-height harmony is preferred over cross-height harmony. While a variety of other patterns exist, this type of pattern is found in a wide range of languages, including Mongolic (Svantesson 1985; Rhodes 2012) and Tungusic language families (Li 1996; Dresher \& Zhang 2005; Walker 2001), as well as a number of Bantu languages (Boyd 2015). In the tableaux to follow, correspondence is marked with subscript indices.

Along with the similarity-sensitive correspondence constraint above, we need a constraint to enforce surface identity between correspondents. A general VV-IDENT[RD] constraint is defined below in (29).

VV-IDENT[RD]

Let $\mathrm{X}$ and $\mathrm{Y}$ be segments in the output $\mathrm{S}$. If $\mathrm{X}$ and $\mathrm{Y}$ correspond, then $\mathrm{X}$ and $\mathrm{Y}$ agree for the feature [round].

In addition to these two constraints, three faithfulness constraints are necessary for the analysis. First, we need a constraint on harmony, for which we use IDENT-OI[RD] (30) (Pater 1999; Rose \& Walker 2005).

(30) IDENT-OI[RD]

For every input-output correspondence pair X-Y, assign a violation for every pair in which output $\mathrm{Y}$ is [+round] and input $\mathrm{X}$ is not.

We also need a constraint banning unrounding of underlyingly [+round] vowels. ${ }^{13}$ We use IDENT-IO[RD] (31) for this purpose.

(31) IDENT-IO[RD]

For every input-output correspondence pair X-Y, assign a violation for every pair in which input $\mathrm{X}$ is [+round] and output $\mathrm{Y}$ is not.

We see the interaction of these four constraints in (32) below. Given an input pair of vowels / $\ldots . . \mathrm{a} /$, harmony applies if ID-OI[RD] is outranked by the other three constraints. Observe in (32) that non-corresponding vowels are given different indices. Thus, the vowels in candidate (a) do not correspond, and are ruled out by CORR-[-HI]. The vowels in candidate (b) correspond, but fail to agree, critically violating VV-ID. Candidate (c) satisfies both CORR-[-HI] and VV-ID, but unrounds / $/ /$ to [a], and since ID-IO[RD] >> ID$\mathrm{OI}[\mathrm{RD}]$, candidate $(\mathrm{c})$ loses to candidate $(\mathrm{d})$.

${ }^{13}$ We assume that both values of the feature may be active, as we pointed out in $\S 3.3$. If, however, [round] is privative (Steriade 1995), the analysis presented in this section does not fundamentally change. 
(32)

\begin{tabular}{|c|c|c|c|c|c|}
\hline & $/ 0 \ldots \mathrm{a} /$ & CORR-[-HI] & $\begin{array}{c}\text { VV-ID } \\
\text { [RD] }\end{array}$ & $\begin{array}{c}\text { ID-IO } \\
{[\mathrm{RD}]}\end{array}$ & $\begin{array}{c}\text { ID-OI } \\
{[\mathrm{RD}]}\end{array}$ \\
\hline a. & $\rho_{x} \ldots a_{y}$ & $* !$ & & & \\
\hline b. & $\rho_{\mathrm{x}} \ldots \mathrm{a}_{\mathrm{x}}$ & & $* !$ & & \\
\hline c. & $a_{x} \ldots a_{x}$ & & & $* !$ & \\
\hline $\mathrm{d}$. & $\partial_{x} \ldots \partial_{x}$ & & & & * \\
\hline
\end{tabular}

Harmony has no inherent directionality in (32), since CORR-[-HI] and VV-ID impose no restrictions on the direction of correspondence or identity (cf. Hansson 2010). To see this, consider (33), where the order of the inputs is reversed. Since all the constraints motivating harmony are symmetrical, the violation profiles below are identical to those in (32).

\begin{tabular}{|c|c|c|c|c|c|}
\hline & /a...o/ & CORR-[-HI] & $\begin{array}{c}\text { VV-ID } \\
{[\mathrm{RD}]}\end{array}$ & $\begin{array}{c}\text { ID-IO } \\
{[\mathrm{RD}]}\end{array}$ & $\begin{array}{c}\text { ID-OI } \\
{[\mathrm{RD}]}\end{array}$ \\
\hline a. & $a_{x} \ldots o_{y}$ & $* !$ & & & \\
\hline b. & $a_{x} \ldots o_{x}$ & & $* !$ & & \\
\hline c. & $a_{x} \ldots a_{x}$ & & & $* !$ & \\
\hline$\Leftrightarrow \mathrm{d}$. & $\partial_{\mathrm{x}} \ldots \partial_{\mathrm{x}}$ & & & & * \\
\hline
\end{tabular}

This basic set of constraints motivates harmony between non-high vowels. However, without the introduction of other constraints, this set of constraints predicts that a non-high round vowel anywhere in the word will trigger rounding on all other non-high vowels. To constrain labial harmony to operate from initial to medial prefixes only, we introduce a positional faithfulness constraint (Beckman 1997).

As discussed in $\$ 3.3 .1$, both initial syllables and roots show prominence by licensing a larger number of contrasts. Initial syllables initiate progressive harmony and resist reduction in hiatus. Similarly, roots initiate ATR harmony and resist labial harmony. The positional faithfulness constraint in (34) prevents vowels in both positions from undergoing harmony.

IDENT-IO-PROM-[RD] For every input-output correspondence pair X-Y occurring in a prominent position (i.e. root or initial syllable), assign a violation for every pair in which the [round] feature value of $\mathrm{X}$ and $\mathrm{Y}$ is not identical.

To see the relative ranking of ID-PROM, consider the tableau in (35). Recall from $\$ 2.3$ that if either vowel of a disyllabic root is round, then the other is as well. In (35), we have assigned the root an underlying form with only one [+round] vowel. The two harmony-driving constraints, CORR-[-HI] and VV-ID, are ranked in the top stratum above the three faithfulness constraints. ID-PROM, in turn, outranks the two more general faithfulness constraints. Candidate (a), the faithful candidate, is ruled out because the two vowels do not correspond, incurring a violation of CORR-[-HI]. Candidate (b) runs afoul of VV-ID because both vowels correspond but fail to agree. Vowels in candidates (c) and (d) both correspond and agree for [round]. Since roots are prominent, changing the value of either vowels input specification incurs a violation of ID-PROM. However, the ranking of ID-IO[RD] >> ID-OI[RD] favors rounding over unrounding. As a result, the constraint ranking below generates the attested output for vowel co-occurrence within roots. Note that it would not matter which vowel was specified for [rd] underlyingly. If one root-internal non-high vowel is 
assigned an underlying [rd] feature, then all root-internal non-high vowels will surface with rounding, which follows from the ranking CORR-[-HI], VV-ID >> ID-IO[RD], ID-OI[RD].

\begin{tabular}{|c|c|c|c|c|c|c|}
\hline & /laks/ & CORR-[-HI] & $\begin{array}{c}\text { VV-ID } \\
{[\mathrm{RD}]}\end{array}$ & $\begin{array}{c}\text { ID-PROM } \\
\text { [RD] }\end{array}$ & $\begin{array}{r}\text { ID-IO } \\
{[\mathrm{RD}]} \\
\end{array}$ & $\begin{array}{c}\text { ID-OI } \\
{[\mathrm{RD}]} \\
\end{array}$ \\
\hline a. & $1 \mathrm{a}_{\mathrm{x}} \mathrm{k} \mathrm{o}_{\mathrm{y}}$ & *! & & & & \\
\hline b. & $1 a_{x} k o_{x}$ & & $* !$ & & & \\
\hline c. & $1 a_{x} k a_{x}$ & & & $*$ & $* !$ & \\
\hline$\leftrightarrow \mathrm{d}$. & $1 \rho_{x} k o_{x}$ & & & $*$ & & $*$ \\
\hline
\end{tabular}

The constraint ranking above also accounts for harmony between non-high prefixes, like (4e), [o-bo-ji] '2sFUT-appear'. In (36), the faithful candidate (a) is ruled out by CORR-[-HI] because the non-high vowels do not correspond. Candidate (b) is suboptimal because the non-high vowels correspond but do not agree for the harmonic feature, violating VV-ID. Candidate (c) incurs a fatal violation of ID-PROM by unrounding the initial syllable vowel. Candidate (d), the attested output, wins because non-high prefix vowels both correspond and agree, with the prominent position controlling harmony. Since /o/ occurs in the prominent initial syllable, it is protected, and harmony proceeds rightward.

\begin{tabular}{|r|c|c|c|c|c|c|}
\hline & /o-be-ji/ & CORR-[-HI] & $\begin{array}{c}\text { VV-ID } \\
{[\mathrm{RD}]}\end{array}$ & $\begin{array}{c}\text { ID-PROM } \\
{[\mathrm{RD}]}\end{array}$ & $\begin{array}{c}\text { ID-IO } \\
{[\mathrm{RD}]}\end{array}$ & $\begin{array}{c}\text { ID-OI } \\
{[\mathrm{RD}]}\end{array}$ \\
\hline $\mathrm{a}$. & $\mathrm{o}_{\mathrm{x}}-\mathrm{be}_{\mathrm{y}}-\mathrm{ji} \mathrm{i}_{\mathrm{z}}$ & $* !$ & & & & \\
\hline $\mathrm{b}$. & $\mathrm{o}_{\mathrm{x}}-\mathrm{be}_{\mathrm{x}}-\mathrm{ji}$ & & $*$ & & & \\
\hline $\mathrm{c}$. & $\mathrm{e}_{\mathrm{x}}-\mathrm{be}_{\mathrm{x}}-\mathrm{ji} \mathrm{y}$ & & & $* !$ & $*$ & \\
\hline $\mathrm{d}$. & $\mathrm{o}_{\mathrm{x}}-\mathrm{bo}_{\mathrm{x}}-\mathrm{ji}$ & & & & & $*$ \\
\hline
\end{tabular}

If we assign the future prefix an underlying [rd] specification in the input to (37), /e-bo-ji/ '3S-FUT-appear', in accordance with OT's requirement that underlying representations are not constrained by the grammar (that is, Richness of the Base), then ID-PROM is necessary to prevent regressive harmony on the initial syllable. Like candidates $(36 \mathrm{a}, \mathrm{b})$, candidates $(36 \mathrm{a}, \mathrm{b})$ below are ruled out due to violations of CORR-[-HI] or VV-ID. Candidate (c) triggers regressive rounding on the initial syllable, and is suboptimal due to a violation of ID-PROM. Candidate (d), which unrounds the medial prefix, wins because unfaithfulness in a medial syllable is preferred over unfaithfulness in the initial syllable. For the first time, we see that ID-PROM must be ranked above ID-IO[RD], since any change to a vowel in a prominent position is worse than unrounding.

\begin{tabular}{|r|c|c:c|c|c|c|}
\hline & /e-bo-ji/ & CORR-[-HI] & $\begin{array}{c}\text { VV-ID } \\
{[\mathrm{RD}]}\end{array}$ & $\begin{array}{c}\text { ID-PROM } \\
{[\mathrm{RD}]}\end{array}$ & $\begin{array}{c}\text { ID-IO } \\
{[\mathrm{RD}]}\end{array}$ & $\begin{array}{c}\text { ID-OI } \\
{[\mathrm{RD}]}\end{array}$ \\
\hline $\mathrm{a}$. & $\mathrm{e}_{\mathrm{x}}-\mathrm{bo}_{\mathrm{y}}-\mathrm{ji} \mathrm{i}_{\mathrm{z}}$ & $* !$ & & & & \\
\hline $\mathrm{b}$. & $\mathrm{e}_{\mathrm{x}}-\mathrm{bo}_{\mathrm{x}}-\mathrm{ji}$ & & $* !$ & & & \\
\hline $\mathrm{c}$. & $\mathrm{o}_{\mathrm{x}}-\mathrm{bo}_{\mathrm{x}}-\mathrm{ji}$ & & & $* !$ & & $*$ \\
\hline $\mathrm{d}$. & $\mathrm{e}_{\mathrm{x}}-\mathrm{be}_{\mathrm{x}}-\mathrm{ji} \mathrm{j}$ & & & & $*$ & \\
\hline
\end{tabular}


In addition to CORR-[-HI], there are two other correspondence constraints that could figure into the analysis: CORR-[+HI], which motivates correspondence for [+hi] vowel pairsand a general CORR-VV, which motivates correspondence for all vowel pairs. Since [+hi] vowel pairs do not participate in harmony we assume that the grammar distinguishes between these three, ranking CORR-[-HI] above CORR-[+HI] and CORR-VV. ${ }^{14}$

As noted above, high vowels are transparent to harmony. Their transparency falls out from the ranking established above, which is demonstrated below. Candidates (a) and (b) in (38) are ruled out, as above, because they contain non-high vowels that either fail to correspond or fail to agree. Candidate (c) avoids harmony by unrounding the vowel in the initial syllable, incurring a fatal violation of ID-PROM. Candidate (d) assimilates the [+hi] prefix, in addition to the medial [-hi] prefix. Cross-height correspondence is not motivated by CORR-[-HI], and the additional violation incurred by ID-OI[RD] for candidate (d) dictates that candidate (e) is the winner.

\begin{tabular}{|c|c|c|c|c|c|c|}
\hline & /o-tí-be-ji / & CORR-[-HI] & $\begin{array}{c}\text { VV-ID } \\
{[\mathrm{RD}]} \\
\end{array}$ & $\begin{array}{c}\text { ID-PROM } \\
\text { [RD] }\end{array}$ & $\begin{array}{c}\text { ID-IO } \\
{[\mathrm{RD}]}\end{array}$ & $\begin{array}{c}\text { ID-OI } \\
{[\mathrm{RD}]} \\
\end{array}$ \\
\hline a & $o_{w}-t_{x}^{\prime}-b e_{y}-j i_{z}$ & $* !$ & & & & \\
\hline $\mathrm{b}$ & $o_{x}-t^{\prime} i_{y}-b e_{x}-j i_{z}$ & & $* !$ & & & \\
\hline c & $e_{x}-t i_{y}-b e_{x}-j i_{z}$ & & & $* !$ & $*$ & \\
\hline d & $o_{x}-t u_{x}-b o_{x}-j i_{y}$ & & & & & $* * !$ \\
\hline 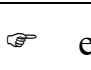 & $o_{x}-t i_{y}-b o_{x}-j i_{z}$ & & & & & $*$ \\
\hline
\end{tabular}

Thus far we have seen two examples with [+hi] roots, which have not entered into correspondence due to their height specification. However, under the current ranking, a [-hi,+rd] root vowel will trigger regressive harmony on non-high prefixes, which is unattested. This problematic prediction is seen below, in (39). Candidates (a-d) are eliminated by the top stratum of constraints. Note that in words with three nonhigh vowels, there are three vowel pairs (V1-V2, V2-V3, and V1-V3). As a result, a maximum of three violations of CORR-[-HI] and VV-ID are possible. However, Hansson (2007) argues that such global evaluation of correspondence produces a range of bizarre predictions, which are remedied if correspondence is instead evaluated in terms of local chains. Thus, a trisyllabic word contains two possible correspondence sequences, V1-V2 and V2-V3, with transitivity of correspondence effectively yielding the long-distance V1-V3 correspondence relation. We evaluate CORR and VV-ID constraints locally below. Candidate (e) violates ID-PROM by unrounding the root vowel. Candidate (f), on the other hand, violates ID-PROM by rounding the initial-syllable vowel. The next constraint, ID-IO[RD] adjudicates between the two, favoring candidate (f) because the ranking favors spreading [+round] over unrounding, all else being equal. In actuality, harmony does not obtain between roots and prefixes, so candidate (f) is marked with a bomb, indicating that the current constraint set favors an unattested output.

\footnotetext{
${ }^{14}$ A second way to analyze harmony would be to use CORR-[ $\alpha$ hi] to drive same-height harmony among both high and non-high vowels in conjunction with a markedness constraint against $[+\mathrm{hi},+\mathrm{rd}]$ vowels. If $*[+\mathrm{hi},+\mathrm{rd}]$ outranked the harmony driving constraints, then harmony among high vowels could be curtailed.
} 
(39)

\begin{tabular}{|c|c|c|c|c|c|c|}
\hline & /a-ba-mo/ & CORR-[-HI] & $\begin{array}{l}\text { VV-ID } \\
{[\mathrm{RD}]}\end{array}$ & $\begin{array}{l}\text { ID-PROM } \\
{[\mathrm{RD}]}\end{array}$ & $\begin{array}{l}\text { ID-IO } \\
\text { [RD] }\end{array}$ & $\begin{array}{l}\text { ID-OI } \\
{[\mathrm{RD}]}\end{array}$ \\
\hline a. & $a_{x}-b a_{y}-m \jmath_{z}$ & $* ! *$ & & & & \\
\hline b. & $a_{x}-b o_{y}-m \partial_{y}$ & $* !$ & & & & * \\
\hline c. & $a_{x}-b a_{x}-m o_{y}$ & $* !$ & & & & \\
\hline d. & $a_{x}-b o_{x}-m o_{x}$ & & $* !$ & & & \\
\hline e. & $a_{x}-b a_{x}-m a_{x}$ & & & $*$ & $* !$ & \\
\hline 类 $\mathrm{f}$. & $o_{x}-b o_{x}-m o_{x}$ & & & & & ** \\
\hline
\end{tabular}

To curtail correspondence, Bennett (2015) introduces a family of LIMITER constraints, among which EDGE constraints prohibit correspondence across certain morphological boundaries. These constraints are effectively equivalent to the earlier autosegmental family of CRISPEDGE constraints (Itô \& Mester 1994, 1999). Using a version of this constraint, VV-EDGE(ROOT), introduced in (40), it is possible to prevent correspondence across a root boundary.

VV-EDGE(ROOT)

Let $\mathrm{S}$ be an output string containing the two morphological categories, root and affix, $\mathrm{R}$ and $\mathrm{A}$, respectively. For each correspondent pair in $\mathrm{S}, \mathrm{X}$ and $\mathrm{Y}$, assign a violation if one correspondent is contained in $\mathrm{R}$ and the other correspondent is not.

VV-EDGE(ROOT) prohibits roots and affixes from corresponding, effectively preventing roots from affecting affixes and vice versa. Since we evaluate correspondence in terms of local chains, VV-EDGE is also evaluated locally rather than globally below. If VV-EDGE dominates CORR-[-HI], then we are able to rightly predict the attested output from (39), which is shown in (41) below. VV-EDGE eliminates all candidates with correspondents across the root boundary, leaving only candidates (e) and (f). Candidate (e) exhibits no correspondence between the two non-high prefixes, and is eliminated. The actual attested output, candidate (f), wins because it exhibits correspondence between prefixes.

\begin{tabular}{|c|c|c|c|c|c|c|c|}
\hline & /a-ba-mo/ & $\begin{array}{c}\text { VV-EDGE } \\
\text { (ROOT) }\end{array}$ & CORR-[-HI] & $\begin{array}{c}\text { VV-ID } \\
{[\mathrm{RD}]}\end{array}$ & $\begin{array}{c}\text { ID-PROM } \\
\text { [RD] }\end{array}$ & $\begin{array}{c}\text { ID-IO } \\
{[\mathrm{RD}]}\end{array}$ & $\begin{array}{c}\text { ID-OI } \\
{[\mathrm{RD}]} \\
\end{array}$ \\
\hline a. & $a_{x}-b o_{x}-m o_{x}$ & $* !$ & & $* *$ & & & \\
\hline b. & $a_{x}-b a_{x}-m a_{x}$ & *! & & & $*$ & $*$ & \\
\hline c. & $o_{x}-b o_{x}-m \rho_{x}$ & $* !$ & & & * & & ** \\
\hline d. & $a_{x}-b o_{y}-m o_{y}$ & $* !$ & $*$ & & & & * \\
\hline e. & $a_{x}-b a_{y}-m o_{z}$ & & $* * !$ & & & & \\
\hline f. & $a_{x}-b a_{x}-m o_{y}$ & & * & & & & \\
\hline
\end{tabular}

By adding VV-EDGE to our constraint set, we successfully accounted for disharmony between a round root and unrounded prefixes. In (42), we show that VV-EDGE also prevents harmony from a [+round] prefix to a root. Crucially, VV-EDGE rules out candidate (b), which involves progressive harmony from the initial syllable onto the root. Candidate (f) is optimal because the domain of correspondence does not extend 
across the root boundary, and within the domain delimited by VV-EDGE, harmony is dictated by the initial syllable.

\begin{tabular}{|c|c|c|c|c|c|c|c|}
\hline & /o-ba-bá/ & $\begin{array}{c}\text { VV-EDGE } \\
\text { (ROOT) }\end{array}$ & CORR-[-HI] & $\begin{array}{c}\text { VV-ID } \\
{[\mathrm{RD}]}\end{array}$ & $\begin{array}{c}\text { ID-PROM } \\
{[\mathrm{RD}]} \\
\end{array}$ & $\begin{array}{c}\text { ID-IO } \\
{[\mathrm{RD}]}\end{array}$ & $\begin{array}{c}\text { ID-OI } \\
{[\mathrm{RD}]}\end{array}$ \\
\hline $\mathrm{a}$ & $o_{x}-b a_{x}-b a_{x}$ & $* !$ & & $* *$ & & & \\
\hline $\mathrm{b}$ & $o_{x}-b \partial_{x}-b \partial_{x}$ & $* !$ & & & * & & $* *$ \\
\hline $\mathrm{c}$ & $o_{x}-b a_{y}-b a_{z}$ & & $* * !$ & & & & \\
\hline d & $o_{x}-b a_{x}-b a_{y}$ & & * & $* !$ & & & * \\
\hline e & $a_{x}-b a_{x}-b a_{y}$ & & $*$ & & $* !$ & * & \\
\hline $\mathrm{f}$ & $o_{x}-b o_{x}-b a_{y}$ & & $*$ & & & & $*$ \\
\hline
\end{tabular}

Using the general $\mathrm{ABC}$ constraint set to encode similarity-sensitivity, along with constraints on domain edges, we have presented a formal analysis of progressive harmony in Tutrugbu. The above set of constraints can motivate root-internal vowel agreement, as well as prefix-internal harmony from the initial syllable, and significantly, these constraints do so without directly encoding progressive directionality.

In the next section we discuss the residual issue of vowel height in the analysis, noting a number of alternatives. We then go on to discuss the larger typology of directionality in vowel harmony.

\section{Discussion}

\subsection{The height of $/ 0^{H} /$ and $/ \varepsilon^{H} /$}

Throughout the previous section we examined [+high] vowels in [+ATR] contexts only, as in (38). In [-ATR] contexts, though, homophonous $1 \mathrm{P}$ and $\mathrm{CM} 8,\left[\mathrm{bo}^{\mathrm{H}}\right]$, do not trigger harmony despite surfacing as mid vowels. We argued in $\S 2.2$ that both $\left[\mathrm{o}^{\mathrm{H}}\right]$ and $\left[\varepsilon^{\mathrm{H}}\right]$ behave as [+high] vowels in Tutrugbu. Four pieces of evidence were discussed. First, these vowels alternate with [+high] vowels, [u] and [i], in ATR harmony. Second, $\left[\mathrm{o}^{\mathrm{H}}\right]$ does not trigger labial harmony, unlike the mid vowels [o] and [o]; in other words, $\left[\mathrm{o}^{\mathrm{H}}\right]$ behaves exactly like $[\mathrm{u}]$. Third, $\left[\varepsilon^{\mathrm{H}}\right]$ does not undergo harmony, unlike $[\mathrm{a}]$ and $[\mathrm{e}]$. Like $\left[\mathrm{o}^{\mathrm{H}}\right]$ above, $\left[\varepsilon^{\mathrm{H}}\right]$ behaves like its [ATR] counterpart, [i]. Fourth, these vowels correspond to [ひ] and [I] in closely-related Tafi.

As briefly noted in $\S 2.2$, ATR harmony also provides evidence that $\left[\mathrm{o}^{\mathrm{H}}\right]$ and $\left[\varepsilon^{\mathrm{H}}\right]$ are phonologically [+high] in the language. ATR harmony is blocked by the combination of an initial-syllable high vowel and a medial non-high prefix (McCollum \& Essegbey 2018; McCollum et al. 2018). In (43a,b), two [-hi] prefixes surface as [+ATR] preceding a [+ATR] root. So, [-high] vowels do not block harmony on their own. In $(43 \mathrm{c}, \mathrm{d})$, two [+high] vowels surface as [+ATR] before a [+ATR] root, indicating that [+high] vowels do not block harmony on their own. When the initial vowel is [-high] and is followed by a [+high] prefix, as in (43e,f), harmony similarly obtains. However, when the initial vowel is [+high] and is followed by a [-high] prefix, harmony is blocked, shown in $(43 \mathrm{~g}, \mathrm{~h}) .{ }^{15}$ Most significantly, $\left[\mathrm{o}^{\mathrm{H}}\right]$ and $\left[\varepsilon^{\mathrm{H}}\right]$ pattern like [+high] vowels. Non-high vowels always undergo ATR harmony in initial syllables, but these two vowels do not. The behavior of $\left[\mathrm{o}^{\mathrm{H}}\right]$ and $\left[\varepsilon^{\mathrm{H}}\right]$ for ATR harmony provides further evidence in favor of an abstract [+high] feature on these vowels.

\footnotetext{
${ }^{15}$ As we noted in relation to (12), a second pattern involves a transparency rather than blocking in this context, e.g. [i-ba-wu] and [bu-ba-wu] for $(43 \mathrm{~g}, \mathrm{~h})$. In this variety of the language, /a/ is conditionally transparent, but the same generalization holds, the behavior of medial /a/ depends on the height of the initial-syllable vowel.
} 
(43)

Conditional blocking in Tutrugbu ATR harmony

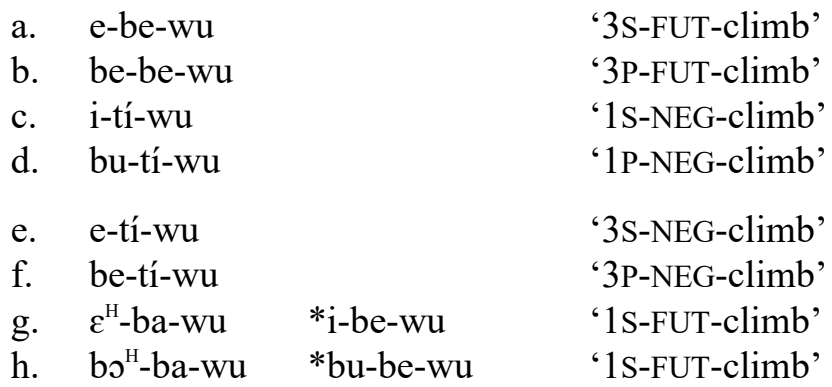

We have encoded the phonological height of $/ \mathrm{s}^{\mathrm{H}} /$ and $/ \varepsilon^{\mathrm{H}} /$ with superscripts to indicate an abstract [+high] feature. We have prioritized accounting for the phonological behavior of these vowels, skirting an analysis of these vowels in [-ATR] contexts. There are other possibilities, though, which to varying degrees account for both the phonological behavior of these vowels and their surface vowel quality. We discuss these in turn. First, the only way we see to account for both the phonological behavior of these vowels and their surface quality is to posit a derivational analysis, where $|\mathrm{I}|$ and $|\mathrm{v}|$ lower to $[\varepsilon]$ and [o] post-lexically. This sort of analysis allows these vowels to behave as [+high] for harmony, but to surface as mid.

Another possibility is to directly encode the details of this alternation in OT. We would need a constraint $*[+h i,-A T R]$ ranked highly to ban output $[\mathrm{I}]$ and $[\mho]$ (what we've labelled $\left[\varepsilon^{\mathrm{H}}\right]$ and $\left[{ }^{\mathrm{H}}\right]$ ). We see two issues with this approach. First, it would predict that these vowels participate in labial harmony in ATR contexts since they are non-high, but that they don't in [+ATR] contexts, since they are high. Perhaps this could be resolved via a paradigm uniformity constraint (Burzio 1996), but the machinery necessary to develop this would, like the derivational analysis just noted, lead us too far afield from the larger issue at hand, prominence and directionality. Second and more troublingly, this analysis predicts that $\left[\varepsilon^{\mathrm{H}}\right]$ should alternate with [e] rather than [i].

Still a third way to account for these facts is to index the set of morphemes that trigger and undergo harmony in a manner consistent with Pater (2000), Finley (2010), and other models of lexical indexation. Using a cloned set of constraints to dictate the (non-)participation of certain morphemes is conceptually similar to what we have proposed here, an abstract height feature. Problematically, though, under a lexical indexation analysis, the morphemes that trigger and undergo harmony all coincidentally share a [-high] feature. The feature-based generalization is lost, and importantly, there is no independent evidence for treating the morphemes that participate in harmony as somehow distinct morphologically from those that do not. In contrast, there is good evidence that the vowels that participate in harmony are treated as [+high] elsewhere in the phonology.

One last possibility is that the vowels $/ \varepsilon^{\mathrm{H}} /$ and $/ \mathrm{o}^{\mathrm{H}} /$ derived from historical ${ }_{\mathrm{I}}$ and ${ }^{*} \mathrm{v}$ are distinguishable from $/ \varepsilon /$ and $/ \mathrm{s} /$ by their surface phonetic properties, exemplifying a near-merger of these historically distinct vowel qualities. To assess the plausibility of a near-merger analysis, we culled thirteen initialsyllable tokens each of $\left[\mathrm{o}^{\mathrm{H}}\right]$ and $[\mathrm{o}]$ from the class 8 prefix $\left[\mathrm{bo}^{\mathrm{H}}\right]$ (which alternates with $[\mathrm{bu}]$ ) and the class 3 prefix, [0] (which alternates with [o]). All tokens were selected from the audio dictionary noted in $\$ 2.1$.

If the surface merger of the historical $*_{v}$ and ${ }^{*}$ o vowels is complete, then we should find no significant differences in F1, F2, or vowel duration. We conducted t-tests on each dependent variable, finding no significant differences for any of these three variables (for $\mathrm{F} 1, \mathrm{t}(24)=1.00, \mathrm{p}=.33$; for $\mathrm{F} 2$, $\mathrm{t}(24)=1.16, \mathrm{p}=$ .26 ; for duration, $\mathrm{t}(24)=-0.75, \mathrm{p}=.46$ ). Descriptive statistics are shown in Table 9. From these results we conclude that $\left[\mathrm{o}^{\mathrm{H}}\right]$ and $[0]$ are acoustically indistinguishable, suggesting complete merger of these vowels on the surface. 
Table 9: Mean F1, F2, and duration for $\left[\mathrm{0}^{\mathrm{H}}\right]$ and [0]

\begin{tabular}{|c|l|l|l|}
\hline Vowel & F1 (SD) & F2 (SD) & Duration (SD) \\
\hline$\rho^{\mathrm{H}}$ & $570(45)$ & $942(118)$ & $133.5(27.7)$ \\
\hline 0 & $585(26)$ & $983(49)$ & $126.5(18.6)$ \\
\hline
\end{tabular}

To test the difference between $\left[\varepsilon^{\mathrm{H}}\right]$ and $[\varepsilon]$, we culled ten examples of each phoneme from the same dictionary. In Tutrugbu (as well as in Tafi), $[\varepsilon]$ does not occur as a prefix, so we examined these vowels in root-final position. Tokens were assumed to derive from historical $*_{I}$ if the Tafi cognate possesses a surface [I]. Similarly, tokens were assumed to derive from ${ }^{*} \varepsilon$ if the Tafi cognate possesses a surface $[\varepsilon]$. We conducted t-tests on each dependent variable, and as above, found no significant differences in F1, F2, or duration (for $\mathrm{F} 1, \mathrm{t}(18)=0.61, \mathrm{p}=.55$; for $\mathrm{F} 2, \mathrm{t}(18)=-0.60, \mathrm{p}=.56$; for duration, $\mathrm{t}(24)=0.56, \mathrm{p}=.58$ ) Descriptive statistics are shown in Table 10.

Table 10: Mean F1, F2, and duration for $\left[\varepsilon^{H}\right]$ and $[\varepsilon]$

\begin{tabular}{|c|l|l|l|}
\hline Vowel & F1 (SD) & F2 (SD) & Duration (SD) \\
\hline$\varepsilon^{\mathrm{H}}$ & $536(82)$ & $2283(126)$ & $160.64(25.5)$ \\
\hline$\varepsilon$ & $559(89)$ & $2227(269)$ & $167.46(29.0)$ \\
\hline
\end{tabular}

Based on these results, there is no phonetic difference we can appeal to in order to differentiate $\left[0^{\mathrm{H}}\right]$ from [0] and $\left[\varepsilon^{\mathrm{H}}\right]$ from $[\varepsilon]$. Since we cannot appeal to near merger to escape the abstract behavior of these two vowels, we have chosen to differentiate these two contrasts with an abstract [+high] feature. This move parallels abstract underlying representations in analyses of languages like Yokuts (Kisseberth 1969; Kenstowicz \& Kisseberth 1979), Hungarian (Vago 1973) and Inupiaq (Kaplan 1981; Compton \& Dresher 2011). This approach to opaque interactions has a long history in generative phonology (see also work in the Toronto School; e.g. Dresher 2009; Compton \& Dresher 2011; Mackenzie 2013). In many cases, like Yokuts (Kisseberth 1969; Kenstowicz \& Kisseberth 1979) and the analysis proposed above, there is very good evidence for positing abstract underlying phonemes.

One last point related to the high vowels is worthy of discussion - our analysis requires that correspondence is not based entirely on acoustic vowel quality. This is distinct from much work within $\mathrm{ABC}$, which assumes that correspondence is sensitive to surface information only (Rose \& Walker 2004; Hansson 2010; Bennett 2015; see also Wayment 2009). If correspondence targets surface mid vowels only without reference to other information, then $/ \varepsilon^{\mathrm{H}} /$ would undergo harmony while its [+ATR] counterpart $/ \mathrm{i} /$ would not. This problematic prediction of a surface-only correspondence relation mirrors the issue noted for the alternative OT analysis sketched above. In addition to ABC, tier- and projection-based models of phonology (Heinz 2010; Heinz et al. 2011; Hansson 2014; McMullin 2016) are also imminently reasonable alternatives to the analysis just presented. All three are able to model transparency and long-distance effects, which is a key part of the analysis just presented.

\subsection{The typology of directionality and prominence}

Under our analysis, the directional behavior of harmony in Tutrugbu is epiphenomenal. As discussed earlier, cases of purely regressive harmony are problematic for Baković's (2000) analysis, which we deemed the strong prominence hypothesis. Hyman's $(2002,2008)$ weak prominence hypothesis, that harmony is either regressive or derivable from prominence, is very similar to the analysis proposed here. However, Hyman allows for only one type of prominence, morphological prominence (i.e. root- or stemcontrol). We, like Walker (2011) and Kaplan (2015), treat stressed syllables and edges as sufficiently prominent to drive harmony too, enlarging the scope of Hyman's analysis. This analysis makes certain predictions, and below we briefly discuss how those fare on the known typology of directionality in harmony. 
For the typology presented below, we use nine constraints, which are listed below in (44). We adopt a generic AGREE[F] constraint (Lombardi 1999; Baković 2000) instead of the ID-VV and CORR constraints used in the analysis for two reasons. First, since the rankings below are largely schematic and ignore much of the feature-related specifics of these patterns, generic ID-VV[F] and CORR-VV constraints operate very similarly to AGREE[F], since they enforce symmetrical harmony to all vowels without any inherent directionality. Second and related to our first reason, collapsing these two constraints, whose activity is only evident when they both outrank the relevant faithfulness constraints, to a single AGREE[F] constraint increases the readability of the typology below.

In addition, we use a harmony-driving constraint that assigns penalties to every instance of $[\mathrm{F}]$ in a given syllable, $\sigma_{\mathrm{x}}$, that disagrees with $[\mathrm{F}]$ in the immediately following syllable, $\sigma_{\mathrm{x}+1}$, to formalize purely regressive harmony, similar to the harmony drivers in Pulleyblank (2002) and Mahanta (2007). To ensure that this sort of constraint would penalize either value of $[\mathrm{F}]$ from spreading, we notate it $*[-\mathrm{F}][+\mathrm{F}] \leftarrow /$ $*[+\mathrm{F}][-\mathrm{F}] \leftarrow$, or R-L-AGREE $[\mathrm{F}]$. In tandem with these two harmony-driving constraints, we deploy a variety of faithfulness constraints, including two general constraints, ID-IO[F] and ID-OI[F], alongside five positional faithfulness constraints to encode the privilege of edges, stems, roots, and stressed syllables. The typology below is not intended to be exhaustive, but simply a comparison between some of the rankings produced by the constraint set and their empirical counterparts.

$$
\begin{aligned}
& \text { Constraint list for typology } \\
& \text { a. AGREe[F] } \\
& \text { b. } \quad *[-\mathrm{F}][+\mathrm{F}] \leftarrow / *[+\mathrm{F}][-\mathrm{F}] \leftarrow \text { or R-L-AGREE[F] } \\
& \text { c. ID-IO[F] } \\
& \text { d. ID-OI[F] } \\
& \text { e. ID-IO } \sigma 1 \\
& \text { f. ID-IO-FINAL } \sigma \\
& \text { g. ID-IO-STEM } \\
& \text { h. ID-IO-ROOT } \\
& \text { i. ID-IÓ́ }
\end{aligned}
$$

The world's languages exhibit at least the following six basic harmony patterns. The first pattern is root-control, which triggers the assimilation of more morphologically peripheral morphemes to the feature value of $[\mathrm{F}]$ in more interior morphemes, typically the root. This can be realized as bidirectional, progressive, or regressive harmony depending on the morphological structure of the language. Second, stress-controlled harmony triggers the assimilation of unstressed vowels to the feature value of $[\mathrm{F}]$ in stressed syllables. We know of two types of stress-controlled patterns, progressive and regressive patterns, shown below; we do not know of any bidirectional stress-controlled harmonies. Third, languages like Tutrugbu exhibit harmony derivable from initial prominence, where the first syllable controls the realization of $[\mathrm{F}]$ in subsequent syllables. Fourth, in some languages the final syllable controls the realization of [F] in preceding syllables, demonstrating final-syllable prominence. Fifth, in a number of African languages, $[+F]$ spreads bidirectionally from a root or suffix. This is often called dominant-recessive harmony, and is not tied to morphological structure in the same way as stem-control, since suffixes may affect roots. Lastly, purely regressive harmony is attested in a number of languages, like Karajá and Assamese. All six of these general patterns are exemplified in (45). 
Root-control

a. Akan ATR harmony (Dolphyne 1988)

$\begin{array}{lll}/ \mathrm{o}-\mathrm{b} \varepsilon-\mathrm{t} \tau-\mathrm{I} / & {[\mathrm{o}-\mathrm{b} \varepsilon-\mathrm{t} \tau-\mathrm{I}]} & \text { '3S-FUT-throw-3S.OBJ' } \\ / \mathrm{o}-\mathrm{b} \varepsilon-\mathrm{tu}-\mathrm{I} / & {[\mathrm{o}-\mathrm{be}-\mathrm{tu}-\mathrm{i}]} & \text { '3S-FUT-dig-3S.OBJ' }\end{array}$

b. Turkish labial harmony (Underhill 1976)

$\begin{array}{lll}/ \text { kiz-in/ } & {[\text { kizin }]} & \text { 'girl-POSS.2S', } \\ / \text { tuz-in/ } & {[\text { tuz-un }]} & \text { 'salt-POSs.2s' }\end{array}$

c. Tutrugbu ATR harmony ${ }^{16}$
/a-ba-bá/
[a-ba-bá]
/a-ba- $\int \mathrm{e} /$
[e-be- $\left.\int \overline{\mathrm{e}}\right]$
'3S-FUT-come'
'3S-FUT-grow'

Stress-control

d. Claro total harmony (Delucchi 2013)

$\begin{array}{lll}/ \text { lim-a/ } & \text { ['li.mi] } & \text { 'file-M.S' } \\ \text { /lan-a/ } & \text { ['la.na] } & \text { 'wool-M.S' } \\ \text { /tcr-a/ } & \text { ['t } \varepsilon . r \varepsilon] & \text { 'earth-M.S' }\end{array}$

e. Brazilian Portuguese height harmony (Bisol 1989)

$\begin{array}{lll}/ \text { pepinu/ } & \text { [pe.' 'pi.nu }] \sim[\text { pi. 'pi.nu }] & \text { 'cucumber' } \\ / \text { formiga/ } & \text { [for.' 'mi.ga] } \sim[\text { fur.' 'mi.ga }] & \text { 'ant' }\end{array}$

Initial prominence

f. Tutrugbu labial harmony
/a-ba-bá/
[a-ba-bá]
'3S-FUT-come'
/o-ba-bá/
[o-bo-bá]
'2S-FUT-come'

Final prominence

g. Yaka height harmony (Hyman 1998)

$\begin{array}{ll}/ \text { kel-umuk-a/ } & {[\text { kel-umuk-a }]} \\ \text { kel-umuk-ene/ } & {[\text { kel-omok-ene }]}\end{array}$

'flip.flop-REV.INT-FV'
'flip.flop-REV.INT-APPL'

Dominant-recessive

h. Diola-Fogny ATR harmony (Sapir 1965)

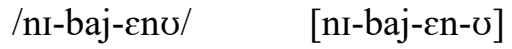
/nI-bəj-øl-ø/ [ni-bəj-ul-u]
'1S-have-CAUS-2P.OBJ'
'1S-have-VENT-2P.OBJ'

Purely regressive

i. Assamese (Mahanta 2007)

$\begin{array}{lll}/ \text { box } / & {[\text { box }]} & \text { 'settle' } \\ \text { /box-oti/ } & {[\text { box-oti }]} & \text { 'settle-NMLZ' }\end{array}$

\footnotetext{
${ }^{16}$ Although suffixation is possible in the language, it is very rare and we have not been able to construct cases to definitively ascertain whether rightward harmony on suffixes is robust, or a lexically specified property of some suffixes.
} 
Looking at some of the patterns generated by our constraint set in Table 11, the first thing to note is that all the attested patterns in (45) are generated with these constraints. Second, there is one empirical pattern that can be generated with more than one constraint ranking, dominant-recessive harmony, as in Diola-Fogny. The first ranking that produces dominant-recessive harmony involves a high-ranking ID$\mathrm{IO}[\mathrm{F}]$ constraint, preserving the harmonic feature wherever it occurs. Coupled with AGREE[F], these two constraints enforce bidirectional harmony from root or affix. The second possible constraint ranking, though, involves two harmony-driving constraints, symmetrical AGREE[F] and the regressive harmonydriver, R-L-AGREE[F]. In this second ranking, harmony is modeled as a default regressive pattern plus stem-controlled harmony on suffixes.

These two analyses are not identical, though. The first predicts that any prefix may host the harmonic feature and in turn, trigger assimilation on the root. This, to our knowledge, is unattested (see also Baković 2000: §5.3; Hall \& Hall 1980). The second analysis predicts that a (non-initial) prefix bearing the feature $[+\mathrm{F}]$ cannot trigger rightward harmony, since harmony under this analysis must either fall out from pure regressive directionality or stem-control. This prediction more accurately accords with the empirical data attested to-date (see Baković 2000: §5.3; Hyman 2002, 2008). As for progressive harmony, as seen above and below, the attested patterns all fall out from morphological prominence (e.g. Turkish), metrical prominence (e.g. Claro), or initial prominence (e.g. Tutrugbu). Since all known progressive patterns are derivable from prominence in some way or another, the presence of some constraint directly encoding a preference for progressive harmony is doubtful at this point.

Table 11: A typology of attested directionality and prominence

\begin{tabular}{|c|c|c|c|c|}
\hline Harmony type & Directionality & Constraint ranking & Example language & Citation \\
\hline $\begin{array}{l}\text { Morphological } \\
\text { prominence } \\
\text { (stem-control) }\end{array}$ & $\begin{array}{l}\text { Bidirectional } \\
\text { Progressive } \\
\text { Regressive* }\end{array}$ & $\begin{array}{c}\text { ID-IO-STEM }>>\text { AGREE[F] }>> \\
\text { ID-IO[F], ID-OI[F] }\end{array}$ & $\begin{array}{c}\text { Akan } \\
\text { Turkish } \\
\text { Tutrugbu }\end{array}$ & $\begin{array}{l}\text { Clements } 1985 \\
\text { Underhill } 1976\end{array}$ \\
\hline \multirow{3}{*}{$\begin{array}{c}\text { Metrical } \\
\text { prominence } \\
\text { (stress-control) }\end{array}$} & Bidirectional & 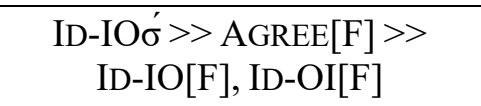 & & \\
\hline & Progressive & $\begin{array}{c}\text { ID-IO } \sigma \dot{ }>>\text { AGREE[F] }>> \\
\text { ID-IO[F], ID-OI[F] }\end{array}$ & Claro & Delucchi 2013 \\
\hline & Regressive & $\begin{array}{c}\text { ID-IO }{ }^{\prime}>>\text { R-L-AGREE[F] }>> \\
\text { ID-IO[F], ID-OI[F] }\end{array}$ & $\begin{array}{c}\text { Brazilian } \\
\text { Portuguese }\end{array}$ & Bisol 1989 \\
\hline \multirow{2}{*}{$\begin{array}{l}\text { Initial } \\
\text { prominence }\end{array}$} & \multirow[t]{2}{*}{ Progressive } & $\begin{array}{c}\text { ID-IO } \sigma 1>> \\
\text { AGREE[F] }>>\text { ID-IO[F], } \\
\text { ID-OI[F] }\end{array}$ & Tutrugbu & \\
\hline & & $\begin{array}{c}\text { ID-IO } \sigma 1>\text { AGREE }[\mathrm{F}]>> \\
\text { ID-IO }[\mathrm{F}], \mathrm{ID}-\mathrm{OI}[\mathrm{F}]\end{array}$ & $\begin{array}{c}\text { Tunen } \\
\text { (function words) }\end{array}$ & Boyd 2015 \\
\hline $\begin{array}{c}\text { Final } \\
\text { prominence }\end{array}$ & Regressive & $\begin{array}{c}\text { ID-IO-FINAL } \sigma>>\text { AGREE[F] } \\
>>\text { ID-IO[F], ID-OI[F] }\end{array}$ & Yaka & Hyman 1998 \\
\hline $\begin{array}{l}\text { Dominant- } \\
\text { recessive }\end{array}$ & Bidirectional & $\begin{array}{c}\text { ID-IO[F], AGREE[F] }>> \\
\text { ID-OI[F] } \\
\text { ID-IO[F], R-L-AGREE[F] }>> \\
\text { ID-IO-STEM }>>\text { AGREE[F] }>> \\
\text { ID-OI[F] }\end{array}$ & Diola-Fogny & Sapir 1965 \\
\hline $\begin{array}{l}\text { Purely } \\
\text { regressive* }\end{array}$ & Regressive & $\begin{array}{c}\text { ID-IO[F], R-L-AGREE[F] >> } \\
\text { ID-IO-STEM, ID-OI[F] }\end{array}$ & Assamese & Mahanta 2007 \\
\hline
\end{tabular}


Generally, the typology produced by these constraints appears to account for the general vowel harmony patterns found in the world's languages. However, one characteristic of the constraint rankings above is that they employ only one positional faithfulness constraint. (Tutrugbu actually requires a rootfaithfulness constraint, too.) When all nine constraints are used to create a full factorial typology in OTSoft (Hayes et al. 2013), 173 possible patterns are produced, many of which utilize more than one positional faithfulness constraint. Many of these produce results that, in our estimation, are much more complicated than attested patterns. As an example, if ID-IO-ROOT, ID-IO-FINAL $\sigma$, and ID-IO- $\sigma$ outrank AGREE[F], then harmony may target all suffixes provided that they are not stressed or in the word-final syllable. This same ranking allows harmony to propagate regressively as long as the target vowel is not stressed. Similarly, if ID-IO-ROOT, ID-IO-FINAL $\sigma$, and ID-IO- $\sigma$ all outrank the regressive harmony-driver R-L-AGREE[F] with a very low-ranking AGREE[F] constraint, then regressive harmony may be triggered by either roots, the final syllable, or the stressed syllable, targeting affixes that are not stressed. In such a language, the final syllable $[+\mathrm{F}]$ vowel might trigger harmony on all post-tonic vowels, while the stressed vowel forces all pretonic suffixes to surface as $[-\mathrm{F}]$, which is in turn blocked by a $[+\mathrm{F}]$ root, which causes all prefixes to surface as $[+\mathrm{F}]$. It is questionable if this sort of pattern is actually learnable.

If the languages of the world reference a single position for harmony, then the typology seems reasonable. If, however, there is no restriction on the number of positions that can be referenced with respect to harmony, then the question becomes why these more complicated patterns are unattested. We can only speculate here, but it is plausible that the unconstrained interactions between the positions used to generate the typology above would require greater expressivity than typically found in vowel harmony (Heinz \& Lai 2013; McCollum et al. 2019; Meinhardt et al. 2020).

\section{Conclusion}

In this paper we have detailed labial harmony in Tutrugbu, demonstrating that it propagates rightward from initial to medial prefixes. In addition to data from harmony, we have marshalled evidence from contrast licensing, hiatus resolution, and ATR harmony to argue that initial syllables are phonologically privileged in the language, and that prominence plays a key role in the harmony pattern. We have also adduced evidence from the larger Ghana-Togo Mountain language family and other known languages exhibiting prefix-initiated harmony, and in all cases the harmony is triggered by initial-syllable vowels only. We generalize from these facts to suggest that prefix-initiated progressive harmony may only originate in initial syllables. By analyzing progressive harmony as prominence-based, we encode rightward harmony indirectly in the analysis. Generally, we suggest that harmony is either prominence-based or purely regressive; as a result, progressive directionality does not need to be directly encoded in the formalism. While the pattern in Tutrugbu is the most robust case of prefix-initiated progressive harmony, it still reinforces the claim that progressive harmony is always derivable from some independent prominence in the language.

\section{References}

Agbetsoamedo, Yvonne. 2014. Aspects of the grammar and lexicon of Selec. Stockholm: Stockholm University dissertation.

Akanlig-Pare, George \& Rogers Krobea Asante. 2016. Vowel harmony in Nkami. Journal of West African Languages 43. 21-44.

Allan, E. J. 1974. A grammar of Buem. London: University of London dissertation.

Archangeli, Diana \& Douglas Pulleyblank. 1994. Grounded phonology. Cambridge, MA: MIT Press.

Archangeli, Diana \& Douglas Pulleyblank. 2002. Kinande vowel harmony: Domains, grounded conditions and one-sided alignment. Phonology 19. 139-188. https://doi.org/10.1017/S095267570200430X.

Archangeli, Diana \& Douglas Pulleyblank. 2007. Harmony. In Paul de Lacy (ed.), The Cambridge handbook of phonology. 353-378. Cambridge: Cambridge University Press. 
Atindogbe, Gratien. 1996. Bankon (A40): Eléments de phonologie, morphologie et tonologie. Cologne: Rüdiger Köppe Verlag.

Baković, Eric. 2000. Harmony, dominance and control. New Brunswick, NJ: Rutgers University dissertation.

Baković, Eric. 2007. A revised typology of opaque generalisations. Phonology 24. 217-259. https://doi.org/10.1017/S0952675707001194.

Barnes, Jonathan. 2006. Strength and weakness at the interface: Positional neutralization in phonetics and phonology. Berlin: de Gruyter.

Becker, Michael, Andrew Nevins \& Jonathan Levine. 2012. Asymmetries in generalizing alternations to and from initial syllables. Language 88. 231-268. https://doi.org/10.1353/lan.2012.0049.

Becker, Michael, Lauren Eby Clemens \& Andrew Nevins. 2017. Generalization of French and Portuguese plural alternations and initial syllable protection. Natural Language \& Linguistic Theory 35. 299-345. https://doi.org/10.1007/s11049-016-9343-y.

Beckman, Jill. 1997. Positional faithfulness, positional neutralisation and Shona vowel harmony. Phonology 14. 1-46. https://doi.org/10.1017/S0952675797003308.

Beckman, Jill. 1998. Positional faithfulness. Amherst, MA: University of Massachusetts dissertation.

Beddor, Patrice \& Handan Yavuz. 1995. The relationship between vowel-to-vowel coarticulation and vowel harmony in Turkish. In Kjell Elenius \& Peter Branderud (eds.), Proceedings of the 13th International Congress of Phonetic Sciences, vol. 2. 44-51. Stockholm: Stockholm University.

Bennett, William G. 2015. The phonology of consonants: Harmony, dissimilation and correspondence. Cambridge: Cambridge University Press.

Bickmore, Lee. 1996. Bantu tone spreading and displacement as alignment and minimal misalignment. Rutgers Optimality Archive 161. http://roa.rutgers.edu/article/view/172.

Bickmore, Lee \& Michael Doyle. 1995. Lexical extraprosodicity in Chilungu. Studies in African Linguistics 24. 85-121.

Bisol, Leda. 1989. Vowel harmony: A variable rule in Brazilian Portuguese. Language Variation \& Change 1. 185-198. https://doi.org/10.1017/S0954394500000065.

Bobuafor, Mercy. 2013. A grammar of Tafi. Utrecht: Utrecht University dissertation.

Boyd, Virginia Lee. 2015. The phonological systems of the Mbam languages of Cameroon with a focus on vowels and vowel harmony. Leiden: Leiden University dissertation.

Burzio, Luigi. 1996. Surface constraints versus underlying representation. In Jacques Durand \& Bernard Laks (eds.), Current trends in phonology: Models and methods, vol. 1.97-122. Paris: European Studies Research Institute.

Casali, Roderic F. 1995. Labial opacity and roundness harmony in Nawuri. Natural Language \& Linguistic Theory 13. 649-663. https://doi.org/10.1007/BF00992854.

Casali, Roderic F. 1997. Vowel elision in hiatus contexts: Which vowel goes? Language 73. 493-533. https://doi.org/10.2307/415882.

Casali, Roderic F. 2002. Nawuri ATR harmony in typological perspective. Journal of West African Languages 29. 3-43.

Casali, Roderic F. 2008. ATR harmony in African languages. Language \& Linguistics Compass 2/3. 496549.

Casali, Roderic F. 2012. [+ATR] dominance in Akan. Journal of West African Languages 39. 33-59.

Chomsky, Noam \& Morris Halle. 1968. The sound pattern of English. New York, NY: Harper \& Row.

Clements, George N. 1976. Vowel harmony in nonlinear generative phonology: An autosegmental model. Harvard University manuscript.

Clements, George N. 1985. Akan vowel harmony: A nonlinear analysis. In Didier Goyvaerts (ed.), African linguistics: Essays in honor of W. M. K. Semikenke, 55-98. Amsterdam: John Benjamins.

Compton, Richard \& B. Elan Dresher. 2011. Palatalization and "strong i" across Inuit dialects. Canadian Journal of Linguistics 56(2). 203-228. https://doi.org/10.1017/S0008413100003145. 
Conklin, Jenna. 2015. The interaction of gradient and categorical processes of long-distance vowel-tovowel assimilation in Kazan Tatar. West Lafayette, IN: Purdue University MA thesis.

Conklin, Jenna \& Olga Dimitrieva. 2018. Phonological impacts on phonetic variation: Vowel harmony and V-to-V coarticulation. Poster presented at the 26th Manchester Phonology Meeting, Manchester, UK.

Dakubu, M. E. Kropp. 2009. Pushing back linguistic time in the Trans-Volta: Movement, assimilation and loss. Journal of West African Languages 36. 5-17.

Dakubu, M.E. Kropp \& Kevin C. Ford. 1988. The central Togo languages. In M.E. Kropp Dakubu (ed.), The languages of Ghana, 119-153. London: Kegan Paul International Limited.

Defina, Rebecca. 2016. Events in language and thought: The case of serial verb constructions in Avatime. Nijmegen: Radboud University dissertation.

Delalorm, Cephas. 2016. Documentation and description of Sekpele: A Ghana-Togo mountain language of Ghana. London: University of London dissertation.

Delucchi, Rachele 2013. Vowel harmony and vowel reduction: The case of Swiss Italian dialects. In Chundra Cathcart, I-Hsuan Chen, Greg Finley, Shinae Kang, Clare S. Sandy \& Elise Stickles (eds.), Proceedings of the 37th Annual Meeting of the Berkeley Linguistics Society (BLS). 61-75. Washington, DC: Linguistic Society of America. https://doi.org/10.3765/bls.v37i1.854.

Dingemanse, Mark. 2011. The meaning and use of ideophones in Siwu. Nijmegen: Radboud University dissertation.

Dolphyne, Florence Abena. 1988. The Akan (Twi-Fante) language: Its sound systems and tonal structure. Accra: Ghana Universities Press.

Dorvlo, Kofi. 2008. A grammar of Logba (Ikpana). Leiden: Leiden Unviersity dissertation.

Dresher, B. Elan. 2009. The contrastive hierarchy in phonology. Cambridge: Cambridge University Press.

Dresher, B. Elan \& Xi Zhang. 2005. Contrast and phonological activity in Manchu vowel systems. Canadian Journal of Linguistics 50. 45-82. https://doi.org/10.1017/S0008413100003662.

Dugast, Idelette. 1971. Grammaire du tunen. Paris: Klincksieck.

Essegbey, James. 2009. Noun classes in Tutrugbu. Journal of West African Languages 35. 37-56.

Essegbey, James. 2010. Does Tutrugbu (Nyagbo) have adjectives? Studies in the Languages of the Volta Basin 6. 149-159.

Essegbey, James. 2012. Aspectual contrasts in Tutrugbu (Nyagbo). In Bruce Connell \& Nicholas Rolle (eds.), Selected Proceedings of the 41st Annual Conference on African Linguistics (ACAL). 40-49. Somerville, MA: Cascadilla

Finley, Greg. 2012. The semantic alignment of modal auxiliaries in Abo. University of California, Berkeley manuscript.

Finley, Sara. 2010. Exceptions in vowel harmony are local. Lingua 120(6). 1549-1566. https://doi.org/10.1016/j.lingua.2009.10.003.

Gblem-Podi, Massanvi. 1996. Déscription systématique de l'Igo: Langue du sud-ouest du Togo. Grenoble, France: Université de Grenoble III dissertation.

Goldsmith, John. 1985. Vowel harmony in Khalkha Mongolian, Yaka, Finnish and Hungarian. Phonology 2. 253-275. https://doi.org/10.1017/S0952675700000452.

Hall, Beatrice L. \& R. M. R. Hall. 1980. Nez Perce vowel harmony: An Africanist explanation and some theoretical questions. In Robert M. Vago (ed.), Issues in vowel harmony. 201-236. Amsterdam: John Benjamins.

Hansson, Gunnar Ólafur. 2007. Blocking effects in agreement by correspondence. Linguistic Inquiry 38. 395-409. https://doi.org/10.1162/ling.2007.38.2.395.

Hansson, Gunnar Ólafur. 2010. Consonant harmony: Long-distance interactions in phonology. Berkeley, CA: University of California Press.

Hansson, Gunnar Ólafur. 2014. (Dis)agreement by (non)correspondence: Inspecting the foundations. Paper presented at $\mathrm{ABC} \leftrightarrow$ Conference, University of California, Berkeley, May 18-19. 
Harley, Matthew Whitelaw. 2005. A descriptive grammar of Tuwuli, a Kwa language of Ghana. London: University of London dissertation.

Hayes, Bruce, Bruce Tesar \& Kie Zuraw. 2013. OTSoft 2.3.3 [software package]. https://www.linguistics.ucla.edu/people/hayes/otsoft/.

Heine, Bernd. 1968. Verbreitung und Gliederung der Togorestsprachen. Berlin: Dietrich Reimer Verlag.

Heinz, Jeffrey. 2010. Learning long-distance phonotactics. Linguistic Inquiry 41. 623-661. https://doi.org/10.1162/LING_a_00015.

Heinz, Jeffrey, Chetan Rawal \& Herbert G. Tanner. 2011. Tier-based strictly local constraints for phonology. In Dekang Lin, Yuji Matsumoto \& Rada Mihalcea (eds.), Proceedings of the 49th Annual Meeting of the Association for Computational Linguistics: Human language technologies, vol. 2. 5864. Portland, OR: Association for Computational Linguistics.

Heinz, Jeffrey \& Regine Lai. 2013. Vowel harmony and subsequentiality. In András Kornai \& Marco Kuhlmann (eds.), Proceedings of the 13th Meeting on the Mathematics of Language (MoL). 52-63. Sofia, BG: Association for Computational Linguistics.

Hulst, Harry van der, Marten Mous \& Norval Smith. 1986. The autosegmental analysis of reduced vowel harmony systems: The case of Tunen. In Frits Beukema \& Aafke Hulk (eds.), Linguistics in the Netherlands. 105-123. Dordrecht: Foris.

Hyman, Larry M. 1988. Underspecification and vowel height transfer in Esimbi. Phonology 5. 255-273. https://doi.org/10.1017/S0952675700002293.

Hyman, Larry M. 1998. Positional prominence and the 'prosodic trough' in Yaka. Phonology 15. 41-75. https://doi.org/10.1017/S0952675798003522.

Hyman, Larry M. 1999. The historical interpretation of vowel harmony in Bantu. In Jean-Marie Hombert \& Larry M. Hyman (eds.), Bantu historical linguistics: Theoretical and empirical perspectives. 235295. Stanford, CA: CSLI Publications.

Hyman, Larry M. 2002. Is there a right-to-left bias in vowel harmony? Paper presented at the Ninth International Phonology Meeting, Vienna.

Hyman, Larry M. 2008. Directional asymmetries in the morphology and phonology of words, with special reference to Bantu. Linguistics 46. 309-350. https://doi.org/10.1515/LING.2008.012.

Hyman, Larry M. 2015. Positional prominence vs. word accent: Is there a difference? UC Berkeley Phonology Lab Annual Report. 86-98.

Itô, Junko \& Armin Mester. 1994. Reflections on CODACOND and alignment. Phonology at Santa Cruz 3. $27-46$.

Itô, Junko \& Armin Mester. 1999. Realignment. In Rene Kager, Harry van der Hulst \& Wim Zonneveld (eds.), The prosody-morphology interface. 188-217. Cambridge: Cambridge University Press.

Jensen, John T. \& Margaret Stong-Jensen. 1973. Ordering and directionality of iterative rules. Research on Language \& Social Interaction 6. 66-90.

Johnson, C. Douglas. 1972. Formal aspects of phonological description. Berlin: Mouton.

Kaplan, Aaron. 2008. Noniterativity is an emergent property of grammar. Santa Cruz, CA: University of California dissertation.

Kaplan, Aaron. 2015. Maximal prominence and a theory of possible licensors. Natural Language \& Linguistic Theory 33. 1235-1270. https://doi.org/10.1007/s11049-014-9273-5.

Kaplan, Lawrence D. 1981. Phonological issues in North Alaskan Inupiaq (Alaska Native Language Center Research Papers 6.) Fairbanks, AK: Alaska Native Language Center.

Kaun, Abigail. 1995. The typology of rounding harmony. Los Angeles, CA: University of California dissertation.

Kaun, Abigail. 2004. The typology of rounding harmony. In Bruce Hayes, Robert Kirchner \& Donca Steriade (eds.), Phonetically based phonology. 87-116. Cambridge: Cambridge University Press.

Kehoe, Margaret \& Carol Stoel-Gammon. 1997. The acquisition of prosodic structure: An investigation of current accounts of children's prosodic development. Language 73. 113-144. 
Kenstowicz, Michael \& Charles Kisseberth. 1977. Topics in phonological theory. San Diego, CA: Academic Press.

Kenstowicz, Michael \& Charles Kisseberth. 1979. Generative phonology: Description and theory. San Diego, CA: Academic Press.

Kiparsky, Paul. 1985. Some consequences of lexical phonology. Phonology 2. 85-138. https://doi.org/10.1017/S0952675700000397.

Kirchner, Robert. 1993. Turkish vowel harmony and disharmony: An Optimality Theoretic account. Rutgers Optimality Archive 4. https://roa.rutgers.edu/article/view/5.

Kirchner, Robert. 2001. Phonological contrast and articulatory effort. In Linda Lombardi (ed.), Segmental phonology in Optimality Theory: constraints and representations. 79-117. Cambridge: Cambridge University Press.

Kisseberth, Charles. 1969. Theoretical implications of Yawelmani phonology. Urbana-Champaign, IL: University of Illinois dissertation.

Krämer, Martin. 2003. Vowel harmony and correspondence theory. Berlin: de Gruyter.

Kropp, M. E. 1967. Lefana, Akpafu and Avatime with English gloss. Accra: Institute of African Studies, University of Ghana.

Kutsch-Lojenga, Constance. 1994. Kibudu a Bantu language with nine vowels. Africana Linguistica 11. $127-133$.

Li, Bing. 1996. Tungusic vowel harmony: Description and analysis. Amsterdam: University of Amsterdam dissertation.

Lightner, Theodore M. 1965. On the description of vowel and consonant harmony. Word 21. 244-250.

Lionnet, Florian. 2016. Subphonemic teamwork: A typology and theory of cumulative coarticulatory effects in phonology. Berkeley, CA: University of California dissertation.

Lombardi, Linda. 1999. Positional faithfulness and voicing assimilation in Optimality Theory. Natural Language \& Linguistic Theory 17. 267-302. https://doi.org/10.1023/A:1006182130229.

Mackenzie, Sara. 2013. Laryngeal co-occurrence restrictions in Aymara: Contrastive representations and constraint interaction. Phonology 30. 297-345. https://doi.org/10.1017/S0952675713000146.

Maddieson, Ian. 1995. Collapsing vowel harmony and doubly-articulated fricatives: Two myths about the phonology of Avatime. UCLA Working Papers in Phonetics 91. 67-84.

Mahanta, Shakuntala. 2007. Directionality and locality in vowel harmony: With special reference to vowel harmony in Assamese. Utrecht: Utrecht University dissertation.

Makeeva, Nadezhda \& Andrey Shluinsky. 2013. Bazovaia glagol'naia sistema iazyka akebu. Afrikanskii sbornik 2013. 359-376.

McCarthy, John J. \& Alan Prince. 1995. Faithfulness and reduplicative identity. University of Massachusetts, Amherst \& Rutgers University manuscript.

McCollum, Adam G. \& Darya Kavitskaya. 2018. Non-iterative vowel harmony in Crimean Tatar. In William G. Bennett, Lindsay Hracs \& Dennis Ryan Storoshenko (eds.), Proceedings of the $35^{\text {th }}$ West Coast Conference on Formal Linguistics (WCCFL). 259-268. Somerville, MA: Cascadilla Press.

McCollum, Adam G. \& James Essegbey. 2018. Unbounded harmony is not always myopic: Evidence from Tutrugbu. In William G. Bennett, Lindsay Hracs \& Dennis Ryan Storoshenko (eds.), Proceedings of the 35th West Coast Conference on Formal Linguistics (WCCFL). 251-258. Somerville, MA: Cascadilla Press.

McCollum, Adam G., Eric Baković, Anna Mai \& Eric Meinhardt. To appear. Unbounded circumambient patterns in segmental phonology. Phonology 37.

McMullin, Kevin James. 2016. Tier-based locality in long-distance phonotactics: Learnability and typology. Vancouver: University of British Columbia dissertation.

Meinhardt, Eric, Anna Mai, Eric Baković \& Adam G. McCollum. 2020. Questioning to resolve transduction problems. Society for Computation in Linguistics 3(48). 453-454. https://doi.org/10.7275/d6yx-f982. 
Mohanan, K.P. 1982. The theory of lexical phonology. Cambridge, MA: Massachusetts Institute of Technology dissertation.

Moskal, Beata. 2015. Domains on the border: Between morphology and phonology. Storrs, CT: University of Connecticut dissertation.

Mous, Maarten. 1986. Vowel harmony in Tunen. In Stewart Bogers, Harry van der Hulst \& Maarten Mous (eds.), The phonological representation of suprasegmentals in African languages. 281-295. Dordrecht: Foris.

Mutaka, Ngessimo M. 1995. Vowel harmony in Kinande. Journal of West African Languages 25. 41-55.

Nevins, Andrew. 2010. Locality in vowel harmony. Cambridge, MA: MIT Press.

Obiri-Yeboah, Michael \& Sharon Rose. 2017. Domains and directionality in Gua vowel harmony. Paper presented at Annual Conference on African Linguistics 48, Bloomington, Indiana.

Pater, Joe. 1999. Austronesian nasal substitution and other NÇ effects. In Rene Kager, Harry van der Hulst \& Wim Zonneveld (eds.), The prosody-morphology interface. 310-343. Cambridge: Cambridge University Press.

Pater, Joe. 2000. Non-uniformity in English secondary stress: The role of ranked and lexically specific constraints. Phonology 17. 237-274. https://doi.org/10.1017/S0952675700003900.

Prince, Alan \& Paul Smolensky. 2004. Optimality Theory: Constraint interaction in generative grammar. Malden, MA: Blackwell. https://doi.org/10.1002/9780470756171.

Pulleyblank, Douglas. 1996. Neutral vowels in Optimality Theory: A comparison of Yoruba and Wolof. Canadian Journal of Linguistics 41. 295-347. https://doi.org/10.1017/S0008413100016601.

Pulleyblank, Douglas. 2002. Harmony drivers: No disagreement allowed. In Julie Larson \& Mary Paster (eds.), Proceedings of the 28th Annual Meeting of the Berkeley Linguistics Society (BLS). 249-267. Washington, DC: Linguistic Society of America. https://doi.org/10.3765/bls.v28i1.3841.

Putten, Saskia van. 2014. Information structure in Avatime. Nijmegen: Radboud University dissertation.

Rhodes, Russell. 2012. Vowel harmony as agreement by correspondence. UC Berkeley Phonology Lab Annual Report. 138-168.

Ribeiro, Eduardo Rivail. 2002. Directionality in vowel harmony: The case of Karajá (Macro-Jê). In Julie Larson \& Mary Paster (eds.), Proceedings of 28th Annual Meeting of the Berkeley Linguistics Society $(B L S)$. 475-485. Washington, DC: Linguistic Society of America. https://doi.org/10.3765/bls.v28i1.3859.

Rose, Sharon \& Rachel Walker. 2004. A typology of consonant agreement as correspondence. Language 80. 475-531. https://doi.org/10.1353/lan.2004.0144.

Rose, Sharon \& Rachel Walker. 2011. Harmony systems. In John A. Goldsmith, Jason Riggle \& Alan C.L. $\mathrm{Yu}$ (eds.), The handbook of phonological theory. 240-290. Malden, MA: Wiley-Blackwell.

Sapir, J. David. 1965. A grammar of Diola-Fogny. Cambridge: Cambridge University Press.

Schuh, Russell G. 1995. Aspects of Avatime phonology. Studies in African Linguistics 24. 31-67.

Soubrier, Aude. 2013. L'ikposso uwi: Phonologie, grammaire, textes, lexique. Lyon: Lyon 2 dissertation.

Stallcup, Kenneth L. 1980. Noun classes in Esimbi. In Larry M. Hyman (ed.), Noun classes in the Grassfields Bantu borderland. 139-153. Los Angeles, CA: Department of Linguistics, University of Southern California.

Steriade, Donca. 1981. Parameters of metrical vowel harmony rules. Massachusetts Institute of Technology manuscript.

Steriade, Donca. 1994. Positional neutralization and the expression of contrast. University of California, Los Angeles manuscript.

Steriade, Donca. 1995. Underspecification and markedness. In John Goldsmith (ed.), The handbook of phonological yheory. 114-174. Malden, MA: Wiley-Blackwell.

Svantesson, Jan-Olof. 1985. Vowel harmony shift in Mongolian. Lingua 67. 283-327. https://doi.org/10.1016/0024-3841(85)90002-6. 
Trubetzkoy, Nikolai S. 1969. Principles of phonology, translated by Christiane A. M. Baltaxe. Berkeley, CA: University of California Press.

Underhill, Robert. 1976. Turkish grammar. Cambridge, MA: MIT Press.

Vago, Robert M. 1973. Abstract vowel harmony systems in Uralic and Altaic languages. Language 49. 579-605. https://doi.org/10.2307/412352.

Walker, Rachel. 2001. Round licensing, harmony, and bisyllabic triggers in Altaic. Natural Language \& Linguistic Theory 19. 827-878. https://doi.org/10.1023/A:1013349100242.

Walker, Rachel. 2011. Vowel patterns in language. Cambridge: Cambridge University Press. https://doi.org/10.1017/CBO9780511973710.

Wayment, Adam. 2009. Assimilation as attraction: Computing distance, similarity, and locality in phonology. Baltimore, MD: Johns Hopkins University dissertation.

Zhang, Jie. 2001. The effects of duration and sonority on contour tone distribution - Typological survey and formal analysis. Los Angeles, CA: University of California dissertation.

Adam G. McCollum

Rutgers University

Department of Linguistics

18 Seminary Place

New Brunswick, NJ 08901 USA

adam.mccollum@rutgers.edu
James Essegbey

University of Florida

Department of Languages, Literatures, and Cultures 1012 Turlington Hall

Gainesville, FL 32611 USA

essegbey@ufl.edu 